\title{
Discovery of the Streptoketides by Direct Cloning and Rapid Heterologous Expression of a Cryptic PKS II Gene Cluster from Streptomyces sp. Tü6314
}

Zhengyi Qian, ${ }^{\mathrm{a}}$ Torsten Bruhn, ${ }^{\mathrm{b}}$ Paul M. D’Agostino, ${ }^{\mathrm{a}, \mathrm{c}}$ Alexander Herrmann, ${ }^{\mathrm{d}}$ Martin Haslbeck, ${ }^{\mathrm{e}}$ Noémi Antal, ${ }^{\mathrm{f}}$ Hans-Peter Fiedler, ${ }^{\mathrm{f}}$ Ruth Brack-Werner, ${ }^{\mathrm{d}}$ and Tobias A. M. Gulder ${ }^{\mathrm{a}, \mathrm{c}^{*}}$

${ }^{a}$ Biosystems Chemistry, Department of Chemistry and Center for Integrated Protein Science Munich (CIPSM), Technical University of Munich, Lichtenbergstraße 4, 85748 Garching bei München, Germany.

b Bundesinstitut für Risikobewertung, Max-Dohrn-Str. 8-10, 10789 Berlin, Germany. 'Technische Universität Dresden, Chair of Technical Biochemistry, Bergstraße 66, 01602 Dresden, Germany.

${ }^{\mathrm{d} H e l m h o l t z ~ Z e n t r u m ~ M u ̈ n c h e n, ~ G e r m a n ~ R e s e a r c h ~ C e n t e r ~ f o r ~ E n v i r o n m e n t a l ~ H e a l t h, ~ I n s t i t u t e ~ o f ~ V i r o l o g y, ~}$ Ingolstädter Landstraße 1, 85764 Neuherberg, Germany.

${ }^{\mathrm{e}}$ Department of Chemistry, Technical University of Munich, Lichtenbergstraße 4, 85748 Garching bei München, Germany.

${ }^{\mathrm{f} I n s t i t u t e}$ of Microbiology, University of Tübingen, Auf der Morgenstelle 28, D-72076 Tübingen, Germany

*Correspondence: tobias.gulder@ ch.tum.de, tobias.gulder@tu-dresden.de 


\section{Table of contents}

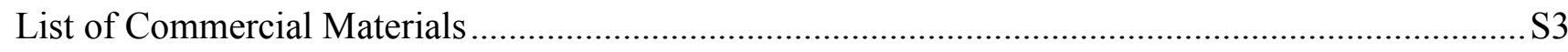

Figure S1. Phylogenetic analysis of $\mathrm{KS}_{\alpha} \mathrm{S}$ and $\mathrm{KS}_{\beta} \mathrm{S}$ from sequenced PKS gene clusters .................... 4

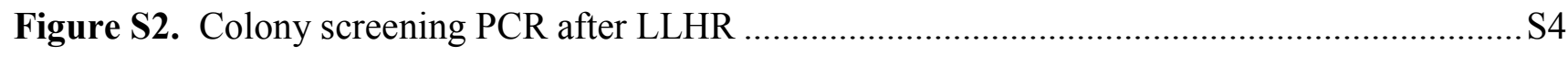

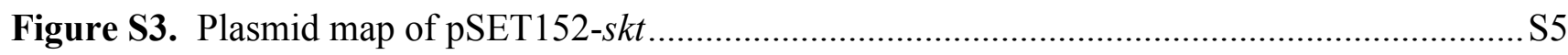

Figure S4. Simulated and authentic restriction enzyme analysis of the pSET152-skt ……...............S6

Figure S5-9. HPLC, -UV, HRMS and NMR data of compound 1...........................................S7-11

Figure S10-14. HPLC, -UV, HRMS and NMR data of compound 2a .......................................S12-17

Figure S15-19. HPLC, -UV, HRMS and NMR data of compound 3a ......................................S18-23

Figure S20-26. HPLC, -UV, HRMS and NMR data of compound 2b .......................................S24-29

Figure S27-29. HPLC, -UV, HRMS and NMR data of compound 3b ......................................S30-32

Figure S30-33. HPLC, -UV, HRMS and NMR data of compound 4 ........................................S33-35

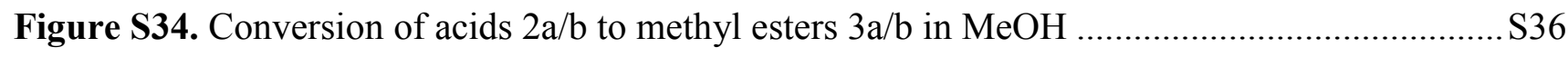

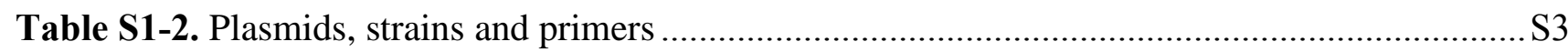

Table S3. Simulated restriction enzyme analysis of the pSET152-skt ............................................ 6

Table S4. ${ }^{1} \mathrm{H}$ and ${ }^{13} \mathrm{C}$ NMR data of UMW5 from the literature ${ }^{6}$ and compound 1 .............................S8

Table S5. ${ }^{13} \mathrm{C}$ NMR data of chemically synthetic S2502, ${ }^{7}$ naturally isolated $\mathrm{S} 2502{ }^{8}$ from the literature

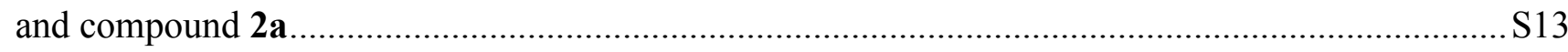

Table S6. ${ }^{1} \mathrm{H}$ NMR data of chemically synthesized S2502, ${ }^{7}$ naturally isolated $\mathrm{S} 2502^{8}$ from the literature and compound 2a

Table S7. ${ }^{13} \mathrm{C}$ NMR data of chemically synthesized S2507, ${ }^{7}$ naturally isolated $\mathrm{S} 2507^{8}$ from the literature and compound $\mathbf{3 a}$

Table S8. ${ }^{1} \mathrm{H}$ NMR data of chemically synthesized S2507, ${ }^{7}$ naturally isolated $\mathrm{S} 2507^{8}$ from the literature and compound 3a. S20

Table S9. ${ }^{1} \mathrm{H}$ and ${ }^{13} \mathrm{C}$ NMR data of streptoketides A (2b) and B (3b) ....................................... S26

Heat of formation (B3LYP/def2-TZVP), number of imaginary frequencies, and cartesian coordinates of $3 \mathbf{a}$. S37

Heat of formation (B3LYP/def2-TZVP), number of imaginary frequencies, and cartesian coordinates of 4 S39

References. S41 


\section{Commercial materials}

The primers were synthesized by Sigma-Aldrich (Taufkirchen, Germany). The restriction enzymes and polymerase (Q5 High-Fidelity DNA polymerase) were purchased from New England Biolabs (Frankfurt am Main, Germany). Plasmid isolation kit (peqGOLD Plasmid Miniprep Kit I, C-Line) and DNA agarose gel extraction kit (peqGOLD Gel Extraction Kit, S-Line) were purchased from VWR (Darmstadt, Germany). The deuterated DMSO was purchased from EurisoTop (Saarbrücken, Germany).

Table S1. Plasmids and strains used in this study

\begin{tabular}{|c|c|c|}
\hline Plasmid or Strain & Characteristics & References \\
\hline \multicolumn{3}{|l|}{ Plasmids } \\
\hline pSET152 & $\phi \mathrm{C} 31$ attP-int, aph(3)II, oriT (RP4), Apr ${ }^{\mathrm{R}}$ & 1 \\
\hline pSET152-skt & pSET152 derivative with skt gene cluster inserted & This study \\
\hline \multicolumn{3}{|l|}{ E. coli } \\
\hline DH5 $\alpha$ & general cloning host strain & Invitrogen \\
\hline GB05-dir & GB2005, araC-BAD-ET $\gamma \mathrm{A}$ & 2 \\
\hline ET12567/pUZ8002 & rec $\mathrm{F}, d a m-, d c m-, \mathrm{Cm}^{\mathrm{R}}, \mathrm{Kan}^{\mathrm{R}}$, carrying plasmid pUZ8002 & 3 \\
\hline \multicolumn{3}{|l|}{ Streptomyces } \\
\hline Tü6314 & Wild-type Streptomyces isolate & This study \\
\hline M1152 & $\begin{array}{l}\text { derived from } S . \text { coelicolor M145: } \Delta a c t, \Delta r e d, \Delta c p k, \Delta c d a, \\
r p o B(\mathrm{C} 1298 \mathrm{~T}), \mathrm{SCP} 1^{-}, \mathrm{SCP} 2^{-}\end{array}$ & 4 \\
\hline M1154 & $\begin{array}{l}\text { derived from } S . \text { coelicolor } \mathrm{M} 145: \Delta a c t, \Delta r e d, \Delta c p k, \Delta c d a, \\
r p o B(\mathrm{C} 1298 \mathrm{~T}), \operatorname{rps} L(\mathrm{~A} 262 \mathrm{G}), \mathrm{SCP} 1^{-}, \mathrm{SCP} 2^{-}\end{array}$ & 4 \\
\hline M1152/pSET152 & $\begin{array}{l}\text { empty pSET152 vector integrated in the M1152 chromosome, } \\
\mathrm{Apr}^{\mathrm{R}}\end{array}$ & This study \\
\hline M1154/pSET152 & $\begin{array}{l}\text { empty pSET152 vector integrated in the M1154 chromosome, } \\
\mathrm{Apr}^{\mathrm{R}}\end{array}$ & This study \\
\hline M1152/skt & skt gene cluster integrated in the M1152 chromosome, $\mathrm{Apr}^{\mathrm{R}}$ & This study \\
\hline M1154/skt & skt gene cluster integrated in the M1154 chromosome, $\mathrm{Apr}^{\mathrm{R}}$ & This study \\
\hline
\end{tabular}

Table S2. Primers used in this study

\begin{tabular}{lll}
\hline Primer & Sequence 5'-3'* & Application \\
\hline \multirow{2}{*}{ pSET152-cap_cluster21-F } & gcgttctcgccgaccggggagacgatccagtgcttgacggacggagtgggGTCAT & Capture vector PCR \\
& AGCTGTTTCCTG & \\
pSET152-cap_cluster21-R & gcggctcgccegtcgtcaccgtccatctgtccacctactacgagaactggACTGGC & Capture vector PCR \\
pSET152_cap_seq-F & CGTCGTTTTAC & PCR screening \\
cap_cluster21_verification_L-R & CGACCCGAAAGGCGATTAAG & PCR screening \\
\hline
\end{tabular}

*Capitalized letters represent the primer binding regions. Lowercase letters represent the homology arms. 

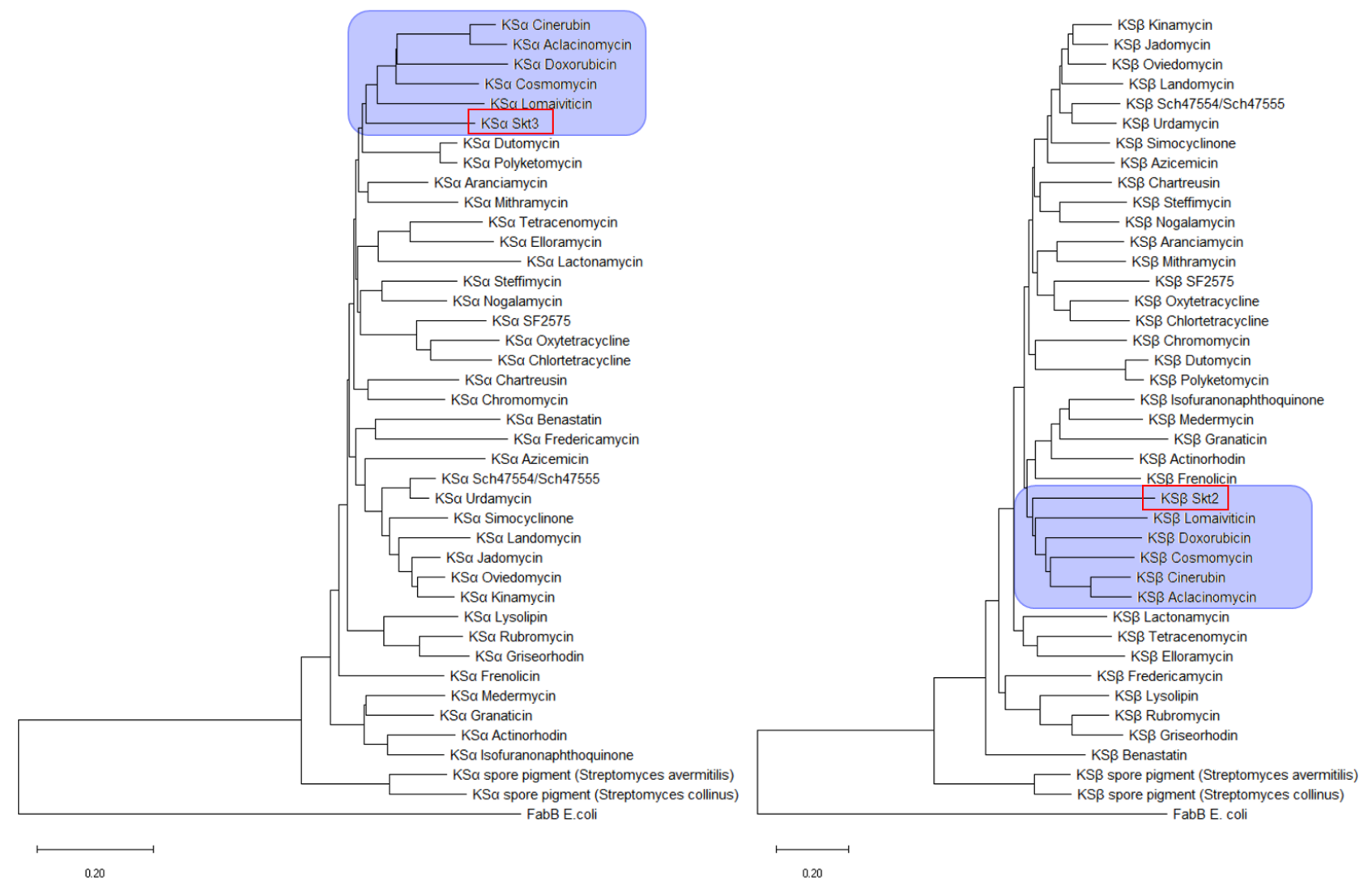

Figure S1. ClustalW-based phylogenetic trees containing $\mathrm{KS}_{\alpha}$ (left) and $\mathrm{KS}_{\beta}$ (right) from sequenced PKS gene clusters. The skt gene cluster $\mathrm{KS}_{\alpha}(\mathrm{Skt} 3)$ and $\mathrm{KS}_{\beta}(\mathrm{Skt} 2)$ are marked by a red rectangle. The branches with colored background have a chain length of 21 carbons. The $f a b B$ gene from E. coli was used as an outgroup. The sequences were downloaded from the MIBiG (Minimum Information about a Biosynthetic Gene cluster) database. ${ }^{5}$

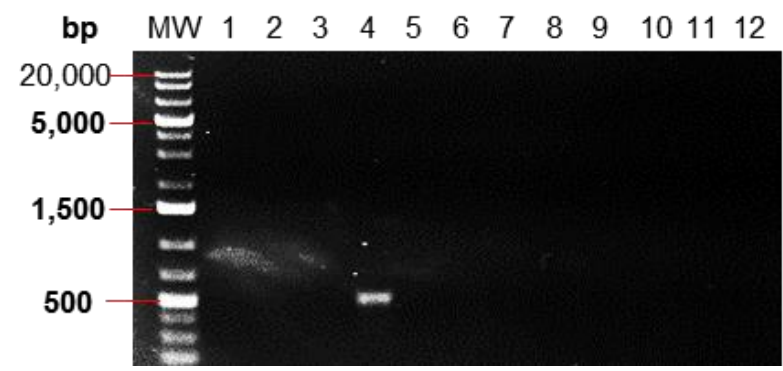

Figure S2. Colony screening PCR after LLHR using primer pairs pSET152_cap_seq-F and cap_cluster21_verification_L-R. Target band has a product size of 508 bp. 


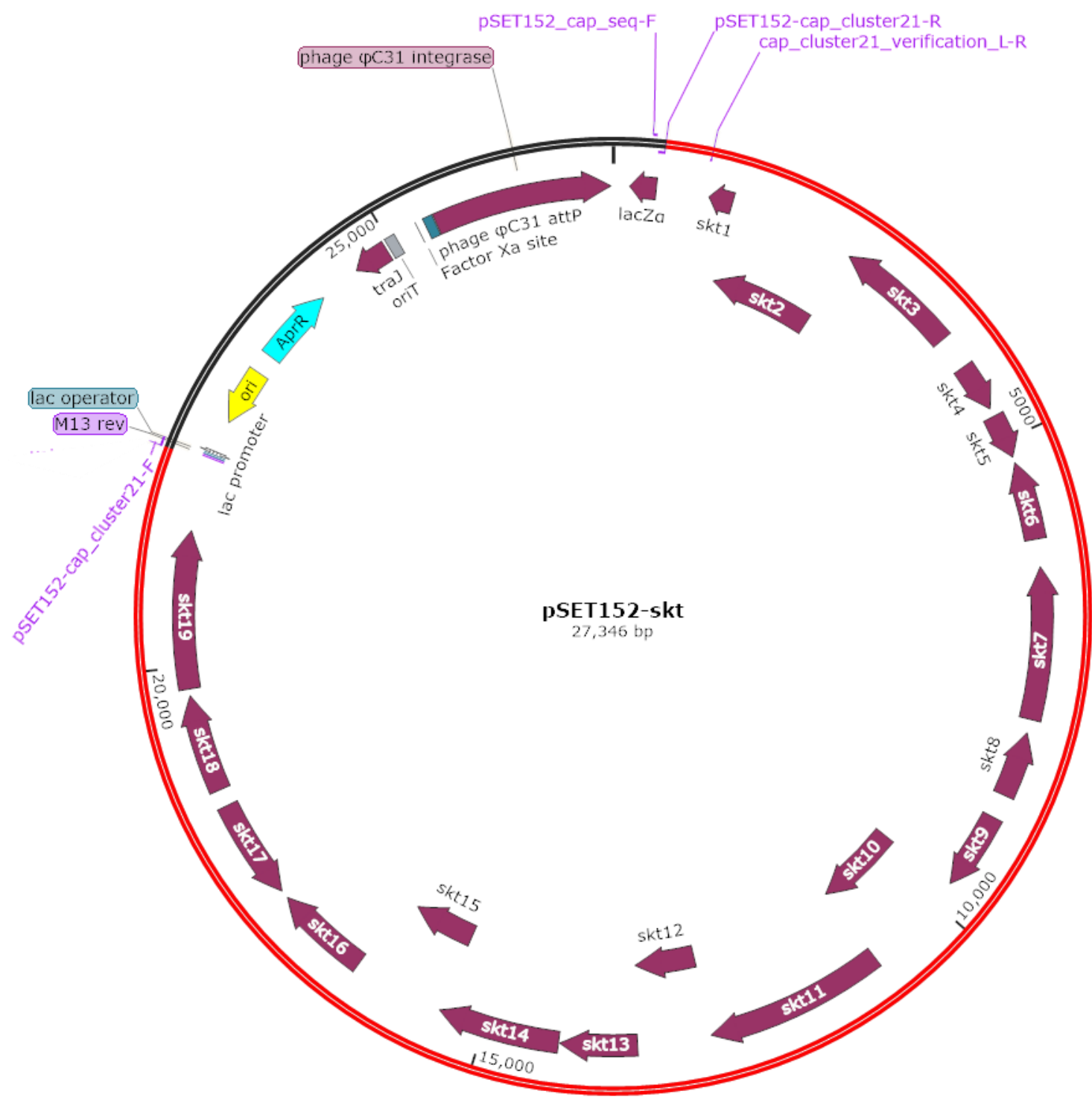

Figure S3. Plasmid map of pSET152-skt with positions of primers used in this study. The part labeled with red indicates the cloned $s k t$ gene cluster. This picture was generated by SnapGene software (GSL Biotech; available at snapgene.com). 


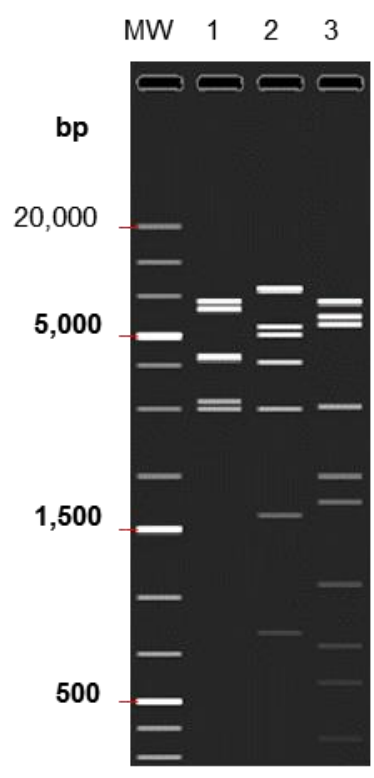

A

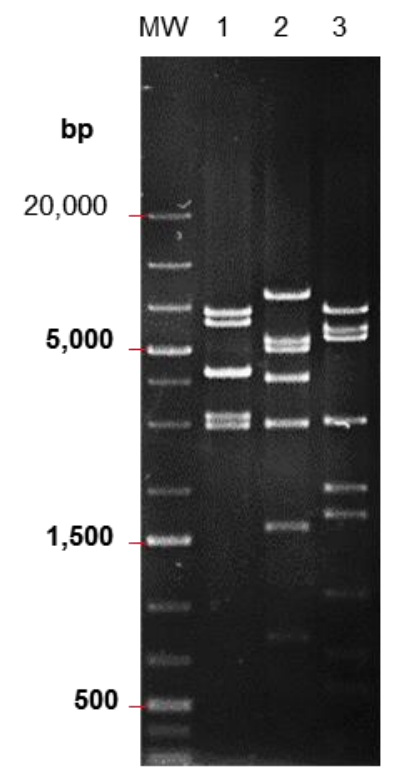

B

Figure S4. (A) Simulated restriction enzyme analysis of the pSET152-skt plasmid digested with BlpI (1), PstI (2) and PvuII (3). See Table S3 for details on expected DNA fragments sizes. This picture was generated by the SnapGene software (GSL Biotech; available at snapgene.com) (B) Authentic restriction enzyme analysis of the captured cluster digested with BlpI (1), PstI (2) and $P v u I I(3)$.

Table S3. Simulated restriction enzyme analysis

\begin{tabular}{cccc}
\hline Enzyme & BlpI (1) & PstI (2) & PvuII (3) \\
\hline Band 1 & $6650 \mathrm{bp}$ & $7488 \mathrm{bp}$ & $6665 \mathrm{bp}$ \\
Band 2 & $6143 \mathrm{bp}$ & $5293 \mathrm{bp}$ & $5763 \mathrm{bp}$ \\
Band 3 & $4245 \mathrm{bp}$ & $4973 \mathrm{bp}$ & $5394 \mathrm{bp}$ \\
Band 4 & $4216 \mathrm{bp}$ & $4033 \mathrm{bp}$ & $3031 \mathrm{bp}$ \\
Band 5 & $3136 \mathrm{bp}$ & $2972 \mathrm{bp}$ & $2012 \mathrm{bp}$ \\
Band 6 & $2956 \mathrm{bp}$ & $1596 \mathrm{bp}$ & $1723 \mathrm{bp}$ \\
Band 7 & & $802 \mathrm{bp}$ & $1086 \mathrm{bp}$ \\
Band 8 & & $189 \mathrm{bp}$ & $733 \mathrm{bp}$ \\
Band 9 & & $578 \mathrm{bp}$ \\
Band 10 & & $361 \mathrm{bp}$ \\
\hline
\end{tabular}



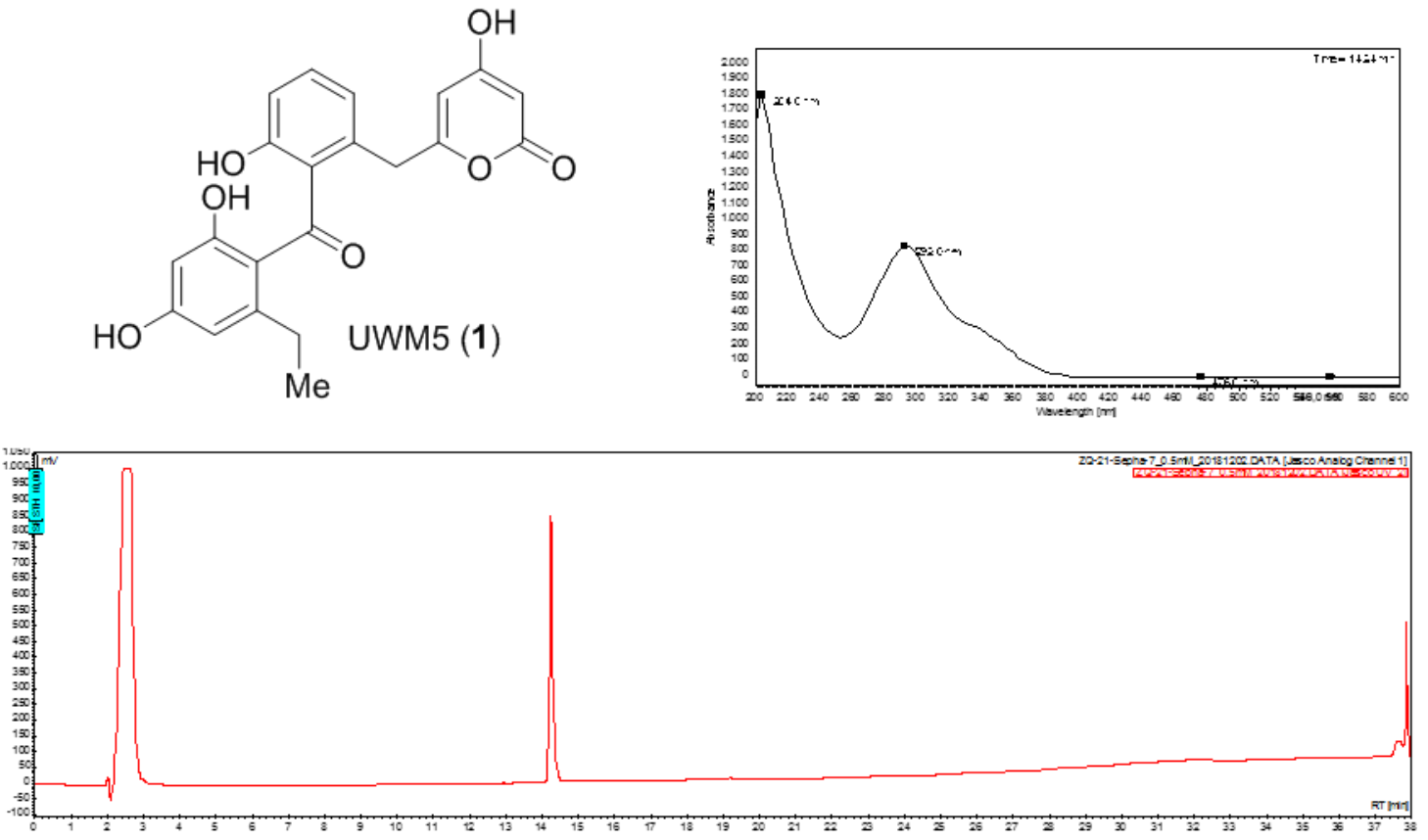

Figure S5. HPLC-UV trace of purified 1 (bottom) and its UV absorption spectrum (top right).

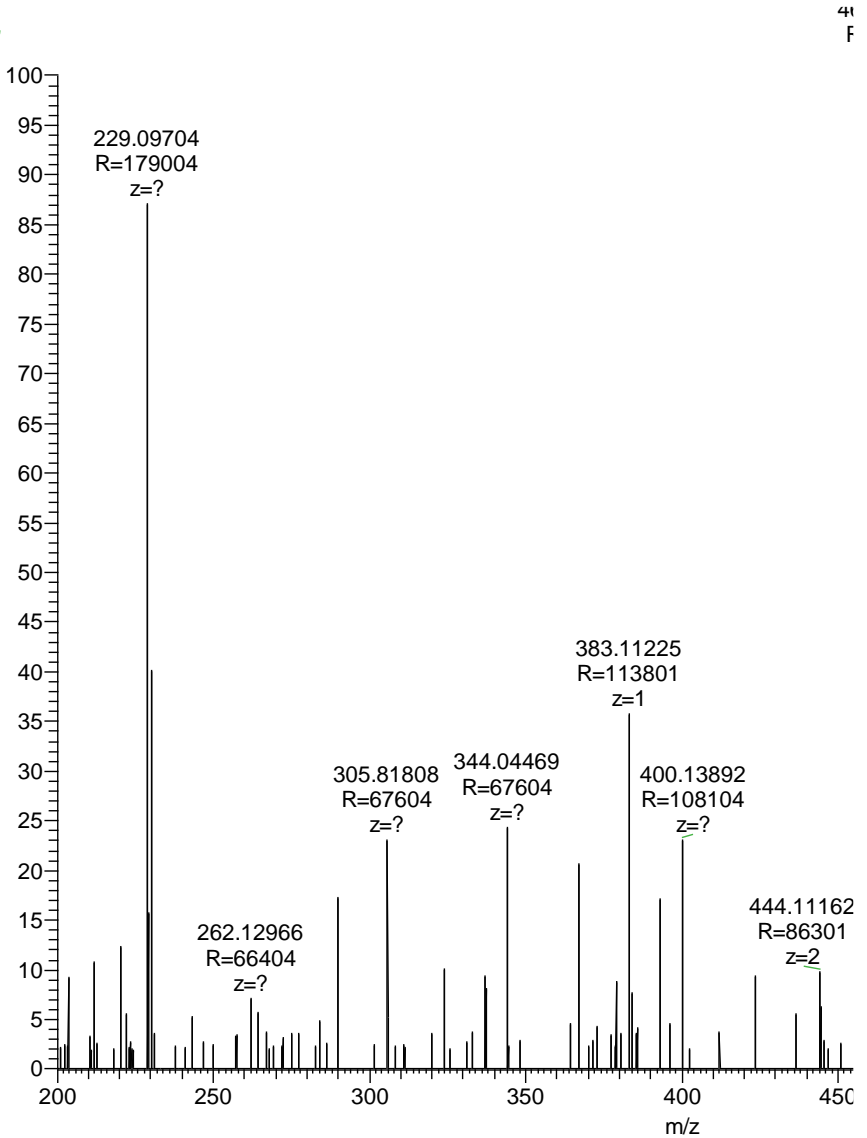

Figure S6. High-resolution ESI-(+) mass spectrum of compound 1. 
Table S4. ${ }^{1} \mathrm{H}(500 \mathrm{MHz})$ and ${ }^{13} \mathrm{C}(125 \mathrm{MHz})$ NMR data of UMW5 from the literature ${ }^{6}$ and compound $\mathbf{1}$, both recorded in DMSO-d6.

\begin{tabular}{|c|c|c|c|c|}
\hline \multirow[b]{2}{*}{ Position } & \multicolumn{2}{|c|}{ UMW5 } & \multicolumn{2}{|c|}{ Compound 1} \\
\hline & ${ }^{1} \mathrm{H}$ (mult, J [Hz]) & ${ }^{13} \mathrm{C}$ & ${ }^{1} \mathrm{H}$ (mult, J [Hz]) & ${ }^{13} \mathrm{C}$ \\
\hline 1 & & $172.1^{* 1}$ & & 163.7 \\
\hline 2 & $5.03(d, 1.8)$ & 87.7 & $5.16(d, 2.1)$ & 88.4 \\
\hline 3 & & $166.9^{* 1}$ & & 170.3 \\
\hline 4 & 5.58 (brs) & 102.2 & $5.65(d, 2.1)$ & 100.9 \\
\hline 5 & & $162.2^{* 3}$ & & 164.5 \\
\hline 6 & $3.56(\mathrm{~s})$ & 36.5 & $3.60(s)$ & 36.6 \\
\hline 7 & & 133.6 & & 133.4 \\
\hline 8 & $6.72(d, 7.9)$ & $131.5^{* 2}$ & $6.73(d, 7.9)$ & 121.0 \\
\hline 9 & $7.19(t, 7.9)$ & $120.7^{* 2}$ & $7.20(t, 7.9)$ & 130.0 \\
\hline 10 & $6.77(d, 7.9)$ & 114.5 & $6.76(d, 7.9)$ & 114.7 \\
\hline 11 & & 154.4 & & 154.6 \\
\hline 12 & - & 130.7 & - & 130.9 \\
\hline 13 & - & 199.3 & - & 199.3 \\
\hline 14 & - & 117.2 & - & 117.5 \\
\hline 15 & - & $164.1^{* 3}$ & - & 162.0 \\
\hline 16 & $6.11(\mathrm{~d}, 2.2)$ & 100.2 & $6.08(d, 2.3)$ & 100.3 \\
\hline 17 & - & 163.5 & - & 161.9 \\
\hline 18 & $6.16(d, 2.2)$ & 108.5 & $6.14(d, 2.3)$ & 108.5 \\
\hline 19 & - & 148.0 & - & 148.0 \\
\hline 20 & $2.34(\mathrm{dt}, 7.4,7.4)$ & 25.9 & $2.34(q, 7.4)$ & 26.0 \\
\hline 21 & $1.00(t, 7.4)$ & 15.1 & $0.97(t, 7.4)$ & 15.3 \\
\hline $3-\mathrm{OH}$ & not reported & - & $11.54(\mathrm{~s})$ & - \\
\hline $11-\mathrm{OH}$ & not reported & - & $9.69(\mathrm{~s})$ & - \\
\hline $15-\mathrm{OH}$ & not reported & - & $11.27(\mathrm{~s})$ & - \\
\hline $17-\mathrm{OH}$ & not reported & - & $10.07(\mathrm{~s})$ & - \\
\hline
\end{tabular}

${ }^{* 1,}{ }^{* 2,}{ }^{* 3}$ : Assignments seem to be interchanged in the original literature. 


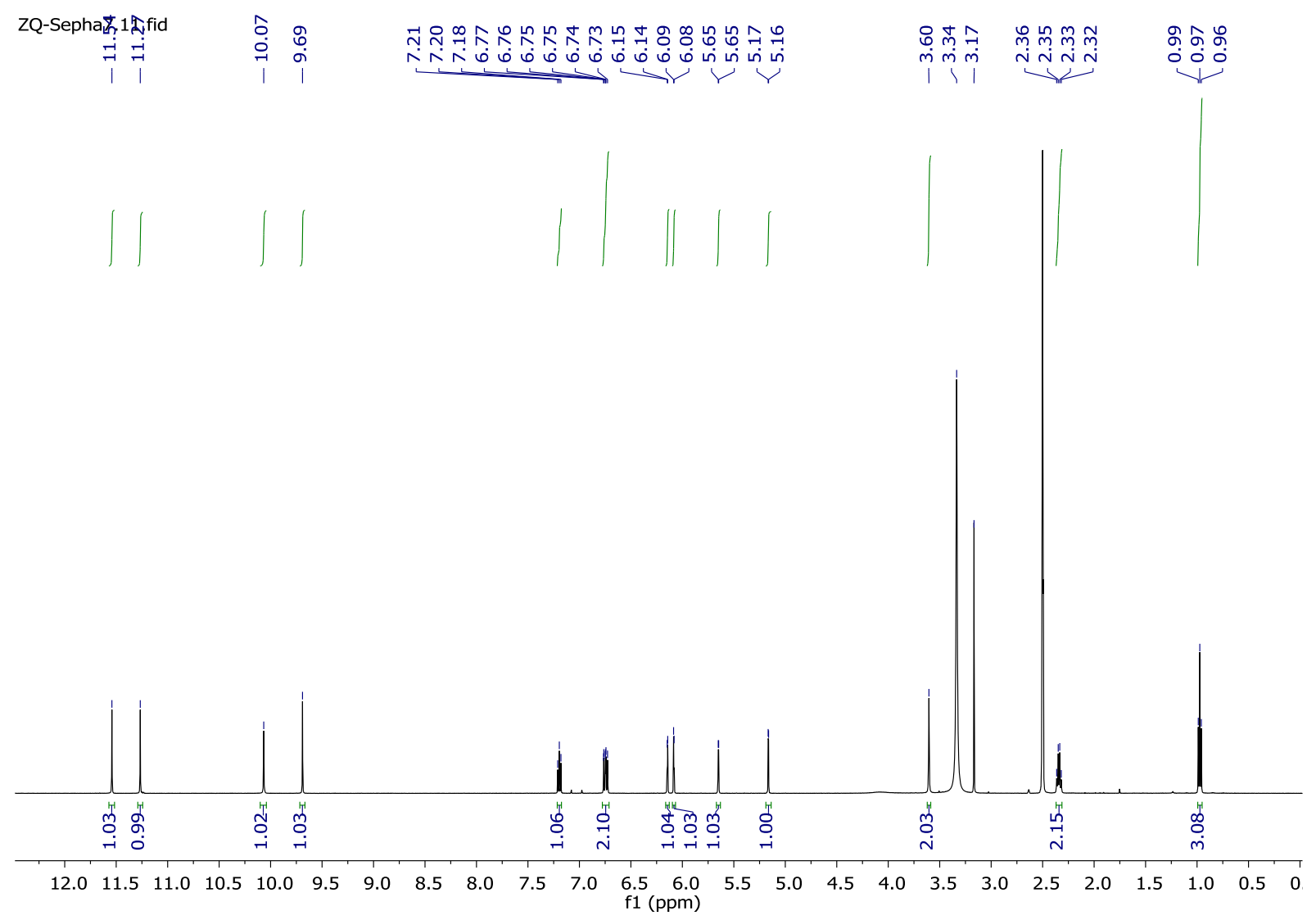

Desfktop.12.fid

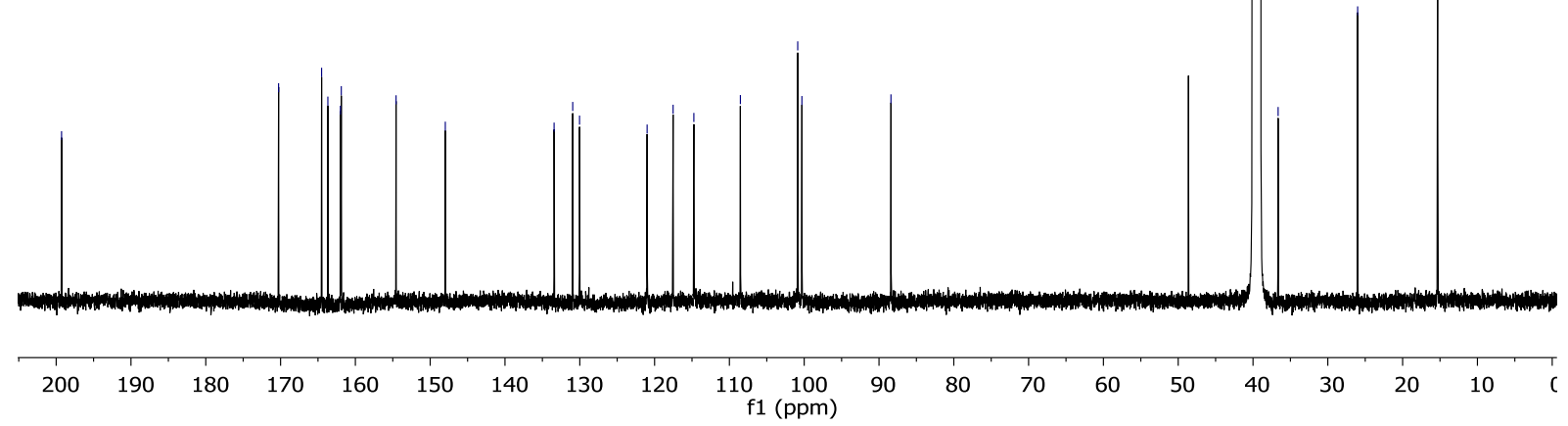

Figure S7. ${ }^{1} \mathrm{H}$ (top) and ${ }^{13} \mathrm{C}$-NMR spectra (bottom) of compound $\mathbf{1}$. 

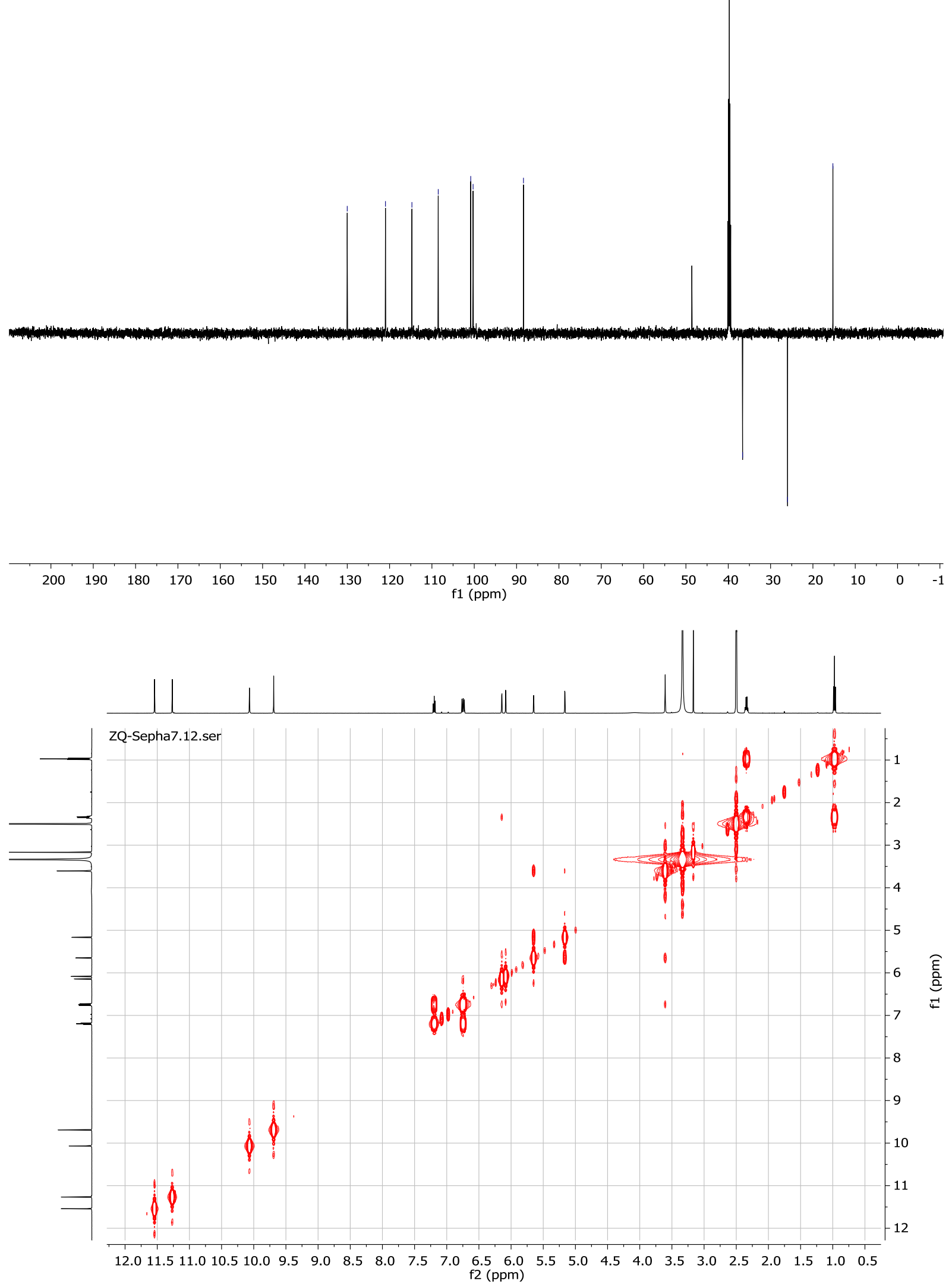

Figure S8. DEPT135 (top) and COSY-NMR spectra (bottom) of compound 1. 

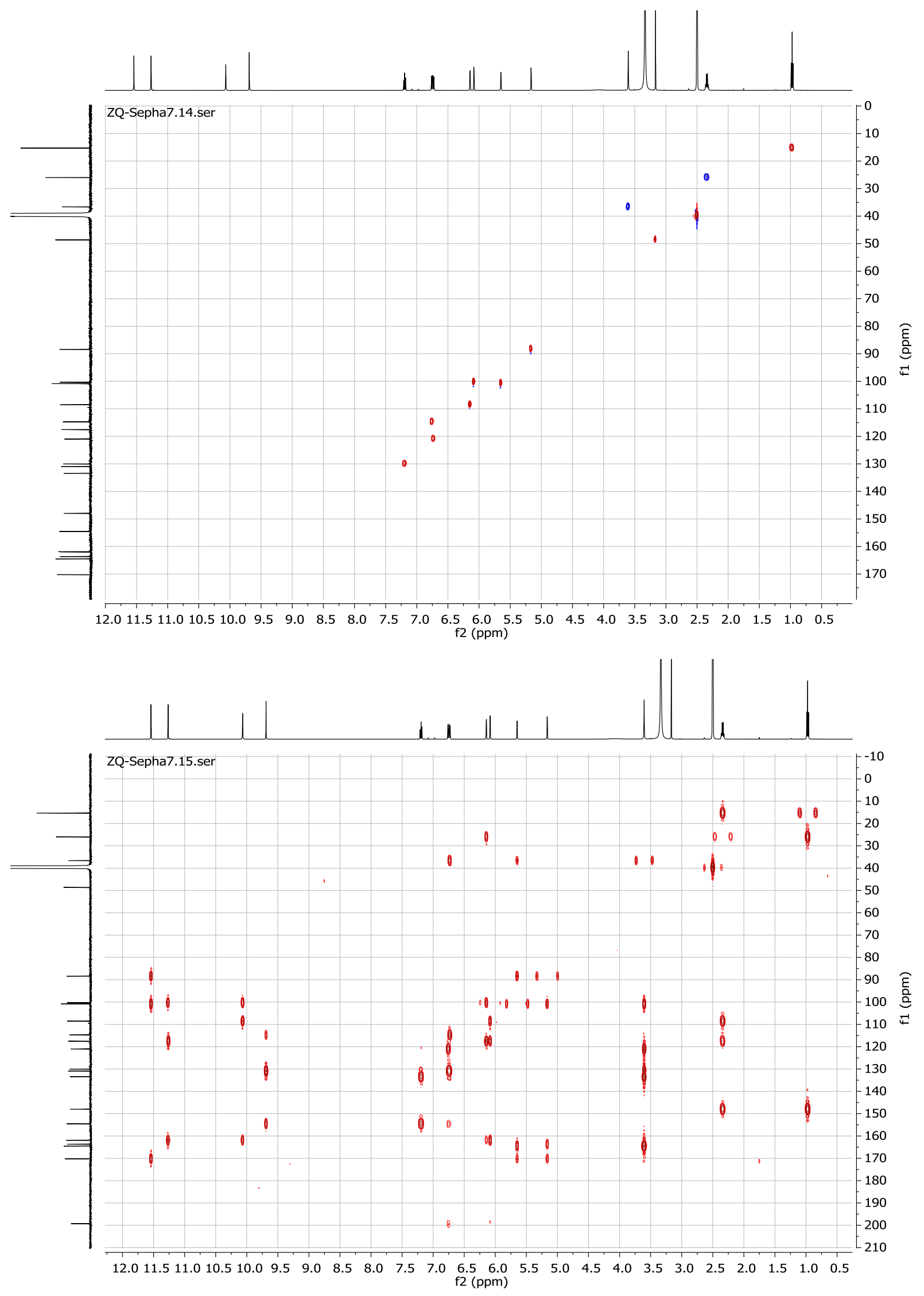

Figure S9. HSQC (top) and HMBC-NMR spectra (bottom) of compound 1. 

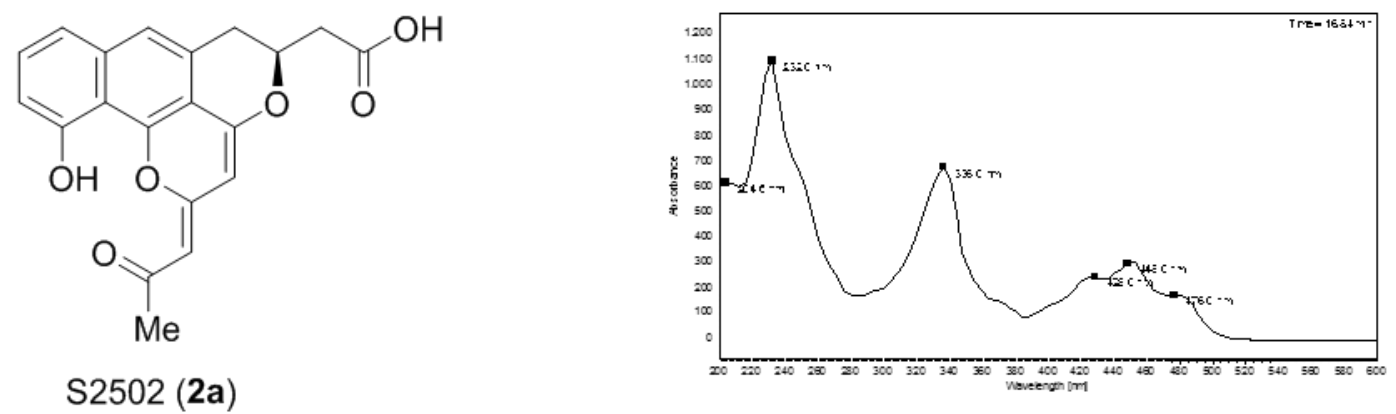

S2502 (2a)

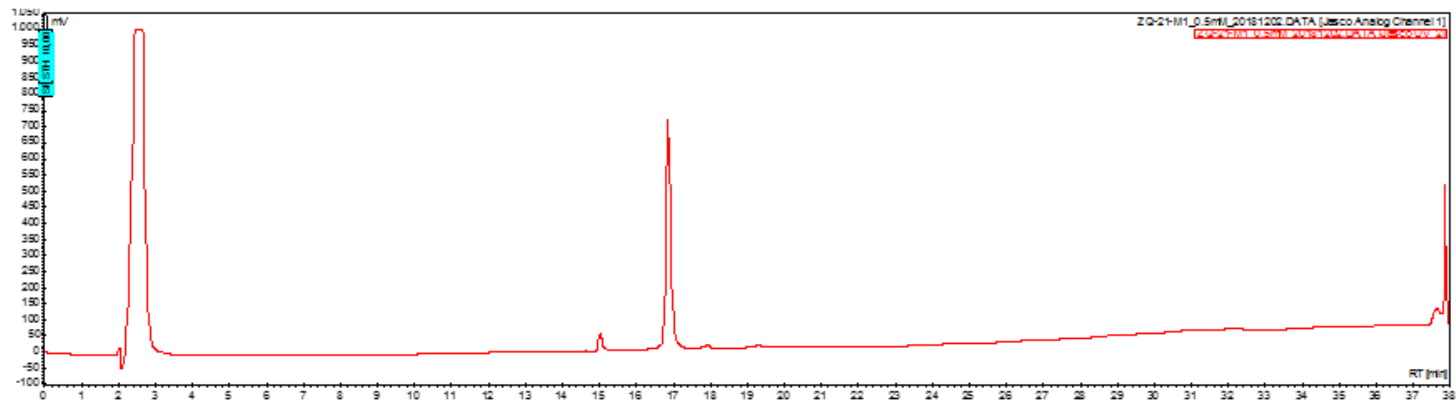

Figure S10. HPLC-UV trace of purified 2a (bottom) and its UV absorption spectrum (top right).

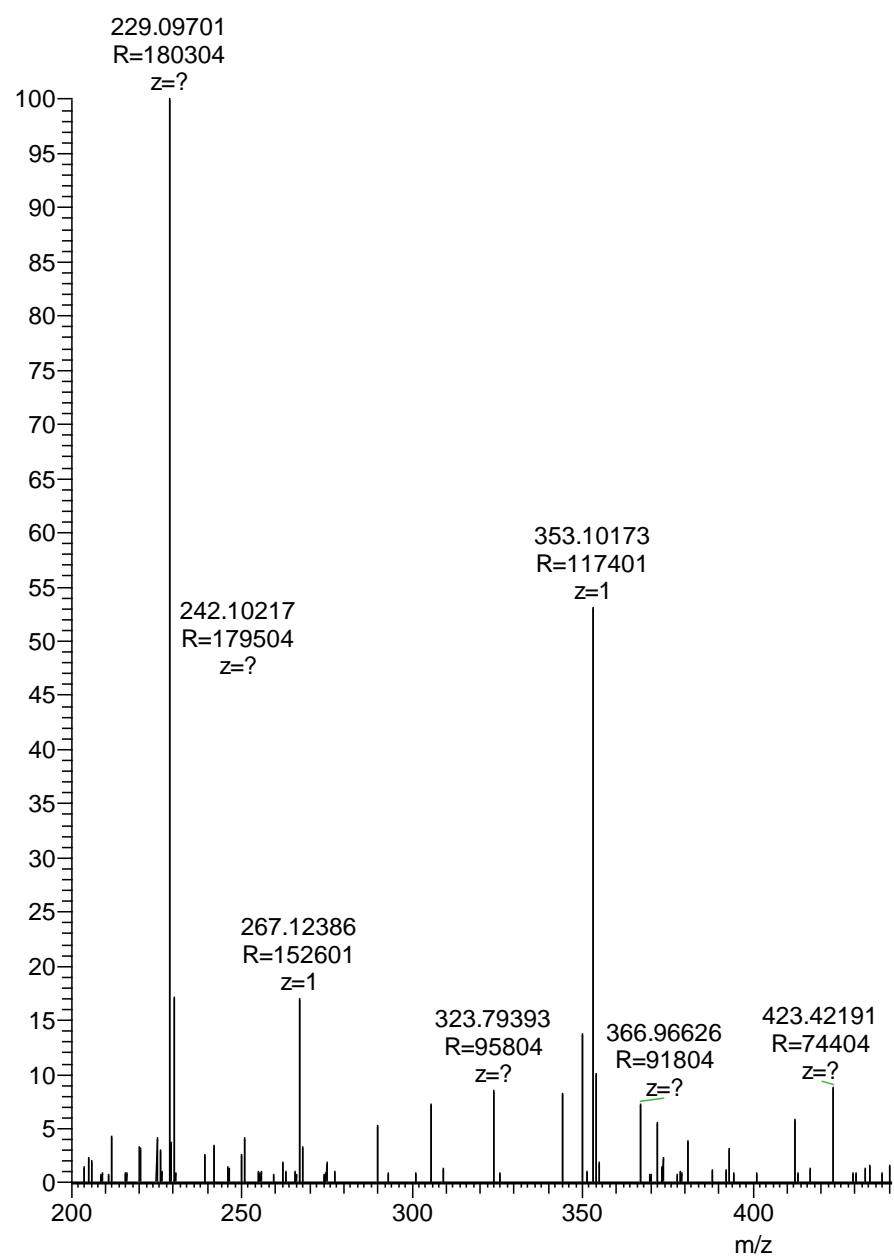

Figure S11. High-resolution ESI-(+) mass spectrum of compound 2a. 
Table S5. ${ }^{13} \mathrm{C}$ NMR data of chemically synthetic S2502, ${ }^{7}$ naturally isolated $\mathrm{S} 2502{ }^{8}$ from the literature and compound 2a, all recorded in DMSO- $\mathrm{d}_{6}$ at $125 \mathrm{MHz}$ (synthetic 2502 and 2a) or $100 \mathrm{MHz}$ (isolated S2502).

\begin{tabular}{|c|c|c|c|}
\hline Position & S2502 (synthetic) & S2502 (isolated) & Compound $2 \mathrm{a}$ \\
\hline 1 & 171.9 & 170.8 & 171.5 \\
\hline 2 & 39.6 & 39.2 & $* 1$ \\
\hline 3 & 70.3 & 74.2 & 75.2 \\
\hline 4 & 32.0 & 31.2 & 31.3 \\
\hline 5 & 127.4 & 125.5 & 126.7 \\
\hline 6 & 122.4 & 121.7 & 122.0 \\
\hline 7 & 137.3 & 136.5 & 136.8 \\
\hline 8 & 118.9 & 118.1 & 118.5 \\
\hline 9 & 130.9 & 130.1 & 130.6 \\
\hline 10 & 113.2 & 112.5 & 112.8 \\
\hline 11 & 154.9 & 154.3 & 154.4 \\
\hline 12 & 112.0 & 111.5 & 111.5 \\
\hline 13 & 150.5 & 149.9 & 150.0 \\
\hline 14 & 107.9 & 106.8 & 107.3 \\
\hline 15 & 158.6 & 157.4 & 157.9 \\
\hline 16 & $97.3^{* 2}$ & $96.8^{* 2}$ & $97.0 * 2$ \\
\hline 17 & 162.6 & 161.7 & 162.1 \\
\hline 18 & $97.1^{* 2}$ & $96.6 * 2$ & $96.8^{* 2}$ \\
\hline 19 & 193.6 & 192.8 & 193.2 \\
\hline 20 & 30.7 & 30.0 & 30.3 \\
\hline 21 & & & \\
\hline
\end{tabular}

\footnotetext{
*1: Signal invisible due to overlap with NMR solvent signal. ${ }^{2}$ : signal assignment might be interchanged.
} 
Table S6. ${ }^{1} \mathrm{H}$ NMR data of chemically synthesized S $2502,{ }^{7}$ naturally isolated $\mathrm{S} 2502^{8}$ from the literature and compound 2 a recorded in DMSO- $\mathrm{d}_{6}$, all recorded in DMSO- $\mathrm{d}_{6}$ at $500 \mathrm{MHz}$ (synthetic 2502 and 2a) or $400 \mathrm{MHz}$ (isolated S2502).

\begin{tabular}{|c|c|c|c|}
\hline Position & S2502 (synthetic) & S2502 (isolated) & Compound $2 \mathrm{a}$ \\
\hline \multicolumn{4}{|l|}{1} \\
\hline \multirow[b]{2}{*}{2} & \multirow[b]{2}{*}{$3.04(\mathrm{~m})$} & $2.91(\mathrm{dd}, 16.1,4.9)$ & \multirow[b]{2}{*}{$2.70(\mathrm{~m})$} \\
\hline & & $2.74(\mathrm{dd}, 16.1,7.8)$ & \\
\hline 3 & $4.70(\mathrm{~m})$ & $4.69(\mathrm{~m})$ & $4.71(\mathrm{~m})$ \\
\hline \multirow{2}{*}{4} & \multirow{2}{*}{$3.30(\mathrm{~m})$} & $3.18(\mathrm{dd}, 16.4,3.1)$ & $3.24(\mathrm{~m})$ \\
\hline & & $3.00(\mathrm{dd}, 16.4,10.6)$ & $3.05(\mathrm{~m})$ \\
\hline \multicolumn{4}{|l|}{5} \\
\hline 6 & $7.48(s)$ & $7.32(\mathrm{~s})$ & $7.50(\mathrm{~s})$ \\
\hline \multicolumn{4}{|l|}{7} \\
\hline 8 & $7.33(d, 8.0)$ & $7.18(d d, 7.8,1.0)$ & $7.33(\mathrm{~d}, 7.9)$ \\
\hline 9 & $7.48(t, 8.0)$ & $7.38(\mathrm{dd}, 7.9,7.8)$ & $7.48(t, 7.9)$ \\
\hline 10 & $6.90(d, 8.0)$ & $6.82(d d, 8.4,1.0)$ & $6.90(d, 7.9)$ \\
\hline \multicolumn{4}{|l|}{11} \\
\hline \multicolumn{4}{|l|}{12} \\
\hline \multicolumn{4}{|l|}{13} \\
\hline \multicolumn{4}{|l|}{14} \\
\hline \multicolumn{4}{|l|}{15} \\
\hline 16 & $6.06(s)$ & $5.90(\mathrm{~s})$ & $6.09(\mathrm{~s})$ \\
\hline \multicolumn{4}{|l|}{17} \\
\hline 18 & $5.54(\mathrm{~s})$ & $5.44(\mathrm{~s})$ & $5.55(\mathrm{~s})$ \\
\hline \multicolumn{4}{|l|}{19} \\
\hline 20 & $2.05(\mathrm{~s})$ & $2.03(\mathrm{~s})$ & $2.05(\mathrm{~s})$ \\
\hline \multicolumn{4}{|l|}{21} \\
\hline $\mathrm{OH}$ & $11.26(\mathrm{~s})$ & $11.16(\mathrm{~s})$ & $11.26(\mathrm{~s})$ \\
\hline
\end{tabular}




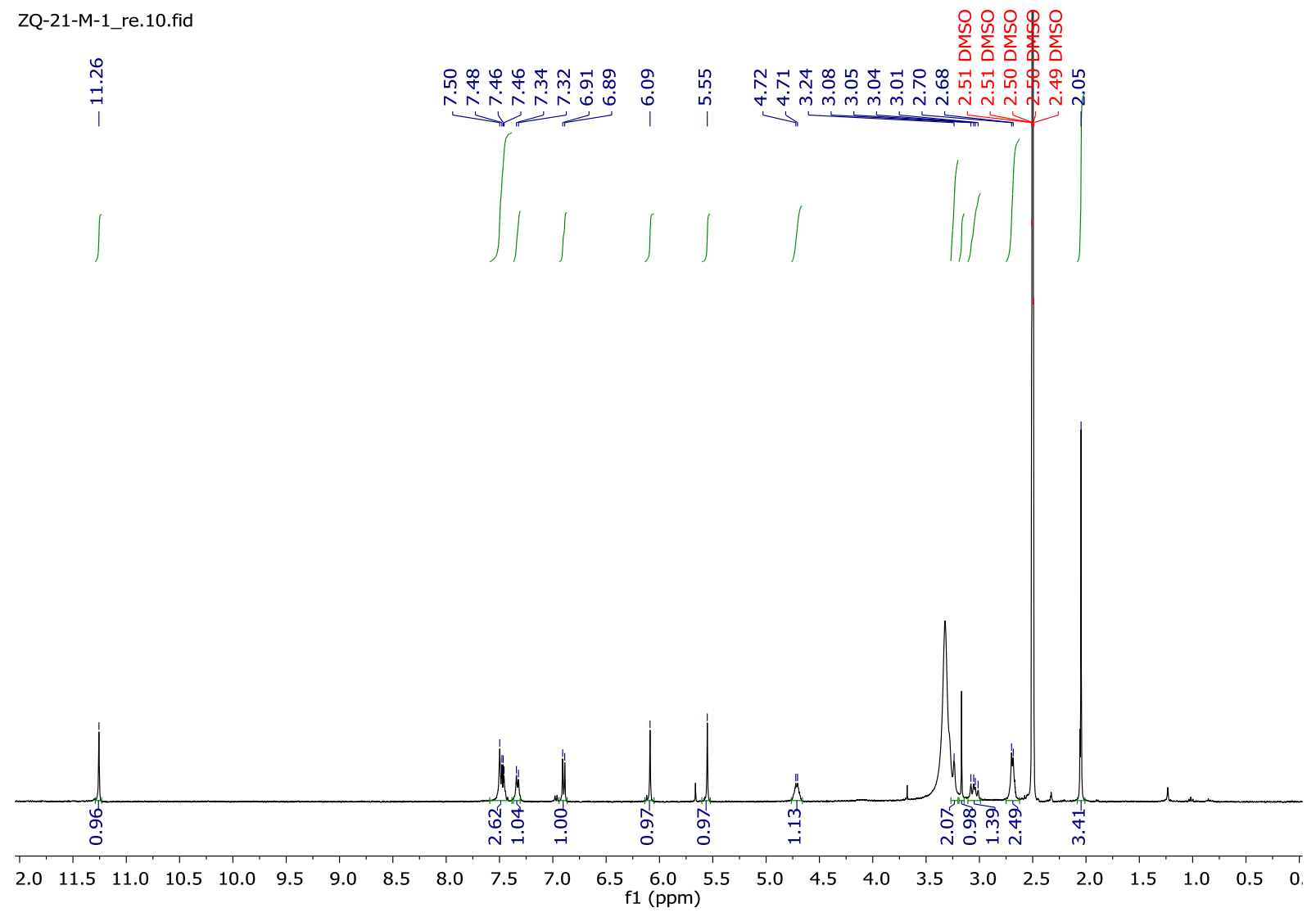

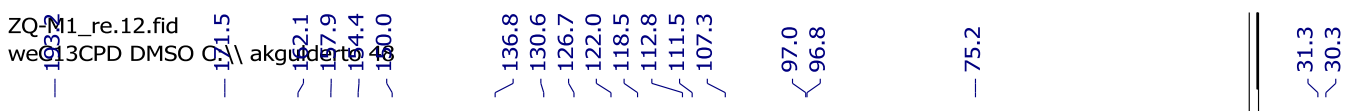

$\begin{array}{lllllllllllllllllllllll}190 & 180 & 170 & 160 & 150 & 140 & 130 & 120 & 110 & \begin{array}{c}100 \\ \mathrm{f} 1(\mathrm{ppm})\end{array} & 90 & 80 & 70 & 60 & 50 & 40 & 30 & 20 & 10 & 0\end{array}$

Figure S12. ${ }^{1} \mathrm{H}$ (top) and ${ }^{13} \mathrm{C}-\mathrm{NMR}$ spectra (bottom) of compound $2 \mathbf{a}$. 


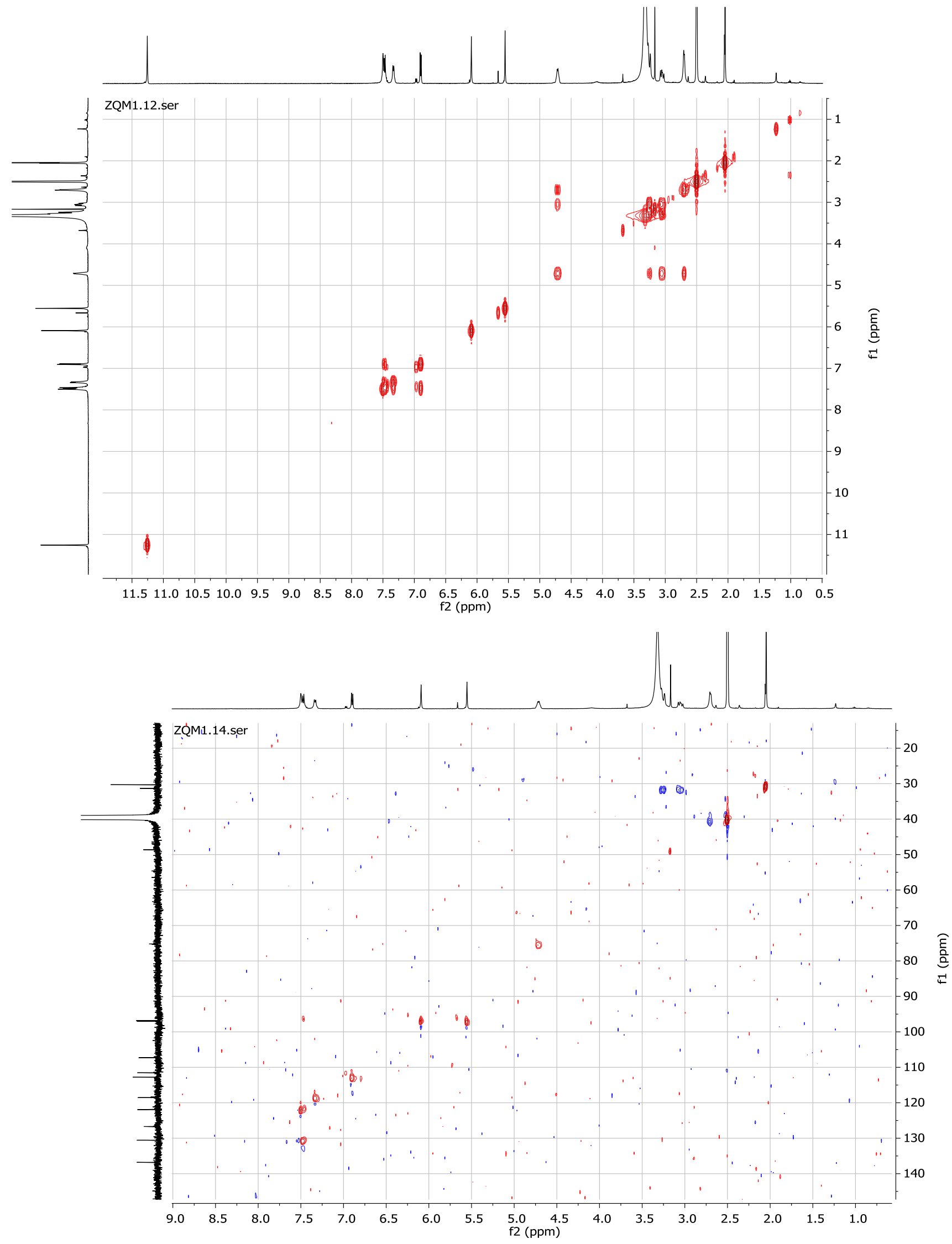

Figure S13. COSY - (top) and HSQC-NMR spectra (bottom) of compound 2a. 


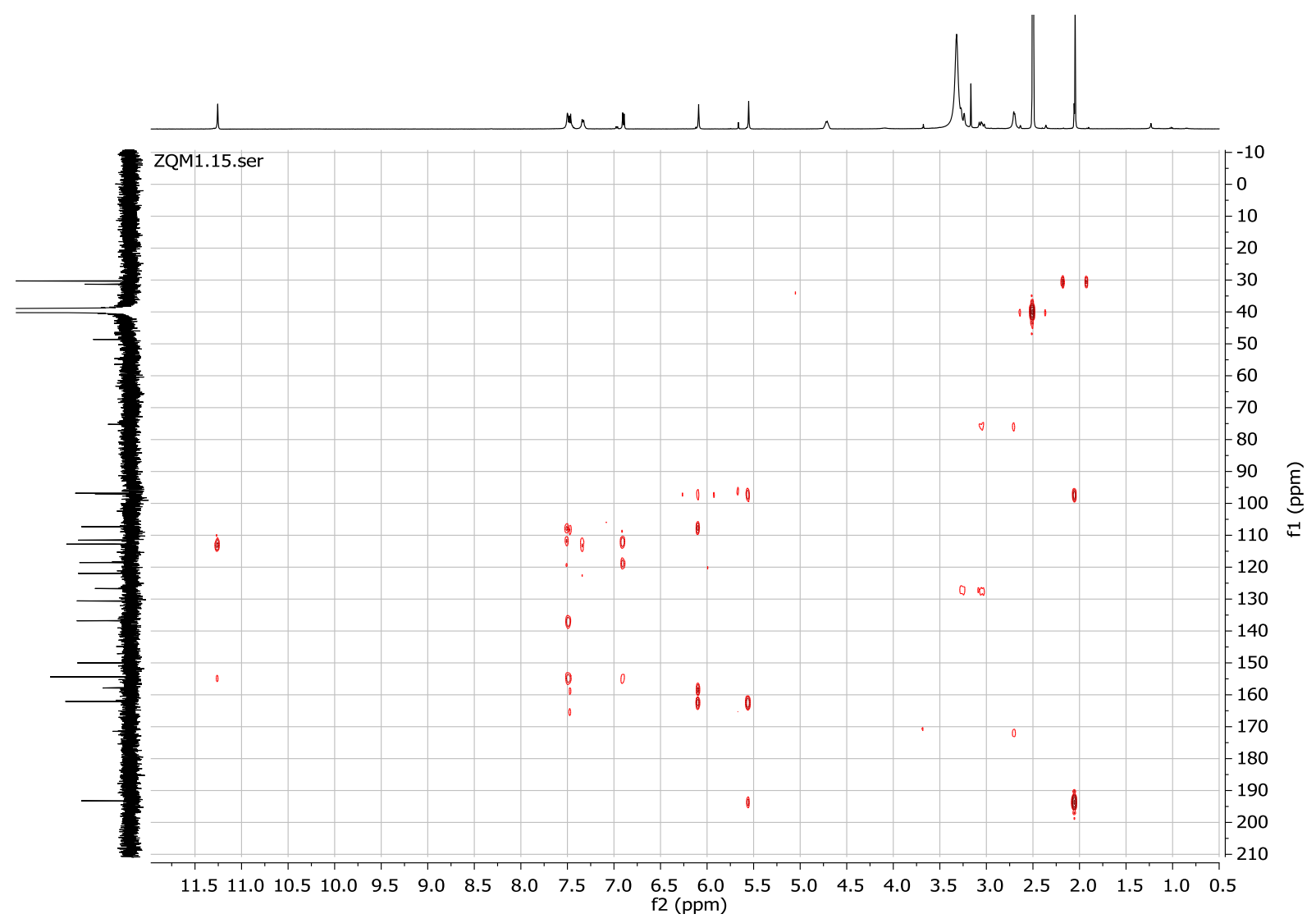

Figure S14. HMBC-NMR spectrum of compound 2a. 

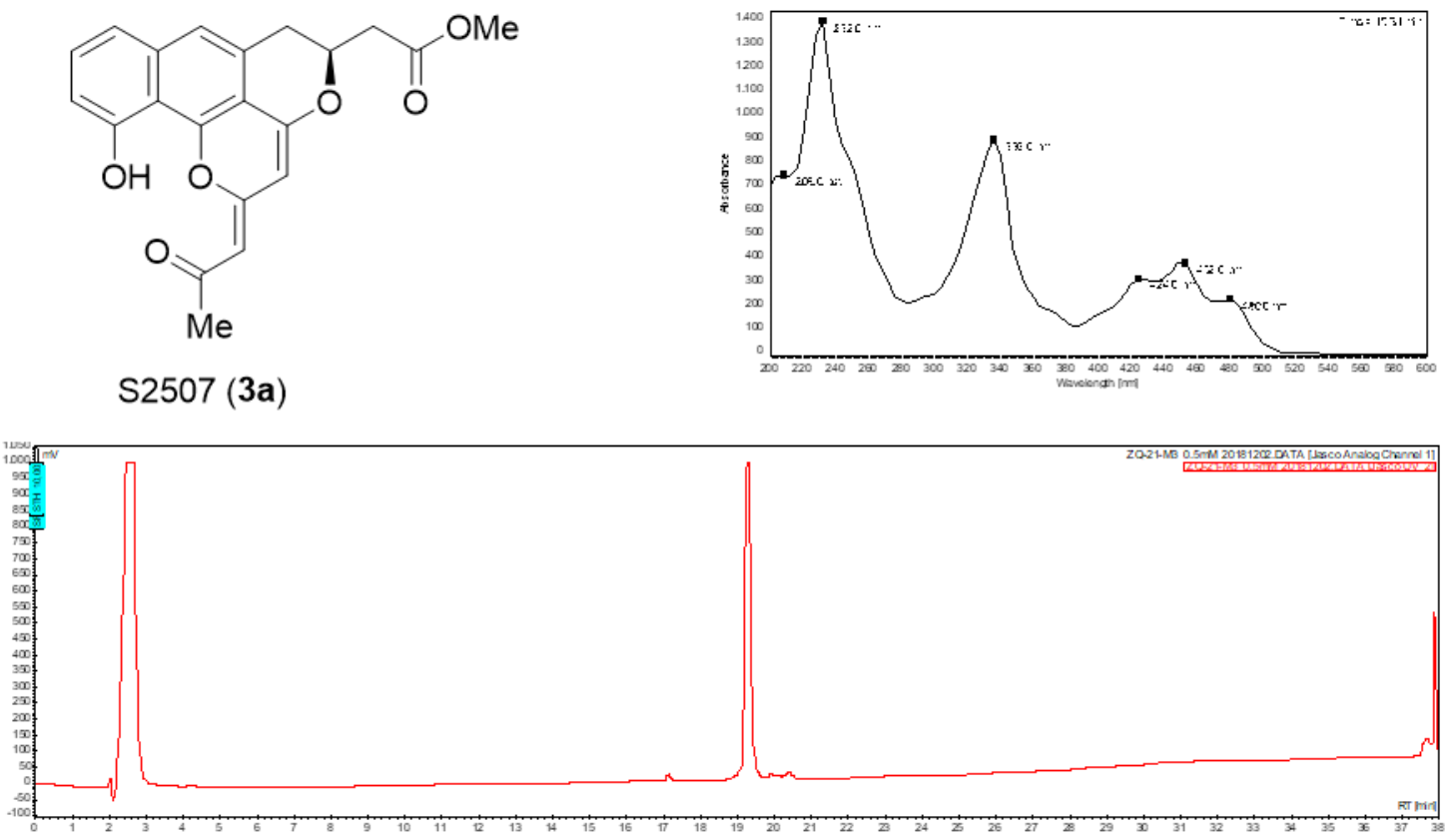

Figure S15. HPLC-UV trace of purified 3a (bottom) and its UV absorption spectrum (top right).

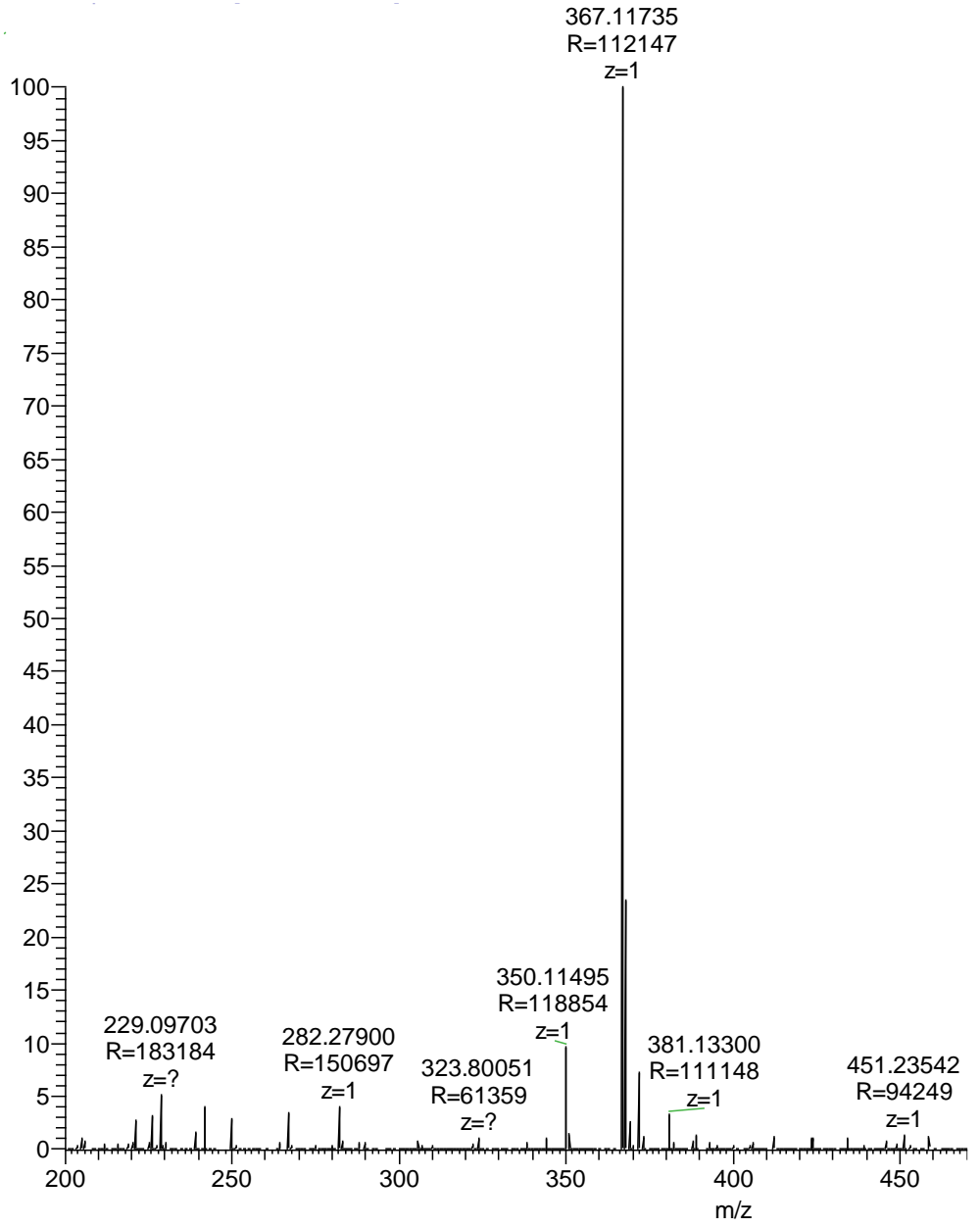

Figure S16. High-resolution ESI-(+) mass spectrum of compound 3a. 
Table S7. ${ }^{13} \mathrm{C}$ NMR data of chemically synthesized S2507 $\left(125 \mathrm{MHz}, \mathrm{CDCl}_{3}\right){ }^{7}$ naturally isolated S2507 $\left(100 \mathrm{MHz}, \mathrm{CDCl}_{3}\right)^{8}$ from the literature and compound 3a recorded in DMSO-d 6 at $125 \mathrm{MHz}$.

\begin{tabular}{|c|c|c|c|}
\hline Position & S2507 (synthetic) & S2507 (isolated) & Compound 3a \\
\hline 1 & 170.0 & 170.0 & 170.1 \\
\hline 2 & 39.6 & 39.6 & 38.8 \\
\hline 3 & 74.0 & 74.0 & 74.4 \\
\hline 4 & 32.2 & 32.2 & 31.1 \\
\hline 5 & 124.7 & 124.7 & 126.3 \\
\hline 6 & 122.1 & 122.1 & 122.0 \\
\hline 7 & 137.1 & 137.1 & 136.8 \\
\hline 8 & 118.2 & 118.2 & 118.6 \\
\hline 9 & 130.9 & 130.9 & 130.6 \\
\hline 10 & 112.6 & 112.6 & 111.5 \\
\hline 11 & 155.5 & 155.5 & 154.3 \\
\hline 12 & 113.7 & 113.7 & 112.8 \\
\hline 13 & 151.1 & 150.0 & 150.0 \\
\hline 14 & 106.9 & 106.9 & 107.2 \\
\hline 15 & 157.6 & 157.6 & 157.4 \\
\hline 16 & $97.6^{*}$ & $97.6^{*}$ & $97.2^{*}$ \\
\hline 17 & 162.2 & 162.2 & 161.9 \\
\hline 18 & $97.1^{*}$ & $97.1^{*}$ & $97.0^{*}$ \\
\hline 19 & 194.2 & 194.3 & 193.3 \\
\hline 20 & 30.4 & 30.4 & 30.3 \\
\hline 21 & 52.2 & 52.2 & 51.8 \\
\hline
\end{tabular}

*2: signal assignment might be interchanged. 
Table S8. ${ }^{1} \mathrm{H}$ NMR data of chemically synthesized S2507 $\left(500 \mathrm{MHz}, \mathrm{CDCl}_{3}\right){ }^{7}$ naturally isolated $\mathrm{S} 2507$ $\left(400 \mathrm{MHz}, \mathrm{CDCl}_{3}\right)^{8}$ from the literature and compound 3a recorded in DMSO-d $\mathrm{d}_{6}$ at $500 \mathrm{MHz}$.

\begin{tabular}{|c|c|c|c|}
\hline Position & S2507 (synthetic) & S2507 (isolated) & Compound $\mathbf{3 a}$ \\
\hline \multicolumn{4}{|l|}{1} \\
\hline \multirow{2}{*}{2} & $2.90(d d, 16.0,7.0)$ & $2.91(\mathrm{dd}, 15.8,7.2)$ & $2.96(d d, 16.3,4.6)$ \\
\hline & $2.74(\mathrm{dd}, 16.0,6.0)$ & $2.75(\mathrm{dd}, 15.8,5.8)$ & $2.86(d d, 16.4,8.1)$ \\
\hline 3 & $4.76(\mathrm{~m})$ & $4.73(\mathrm{~m})$ & $4.77(\mathrm{~m})$ \\
\hline \multirow{2}{*}{4} & $3.18(\mathrm{dd}, 16.0,3.0)$ & $3.20(\mathrm{dd}, 16.0,3.0)$ & $3.23(\mathrm{dd}, 16.5,3.0)$ \\
\hline & $3.03(\mathrm{dd}, 16.0,10.0)$ & $2.91(\mathrm{dd}, 15.8,7.2)$ & $3.08(d d, 16.5,10.5)$ \\
\hline \multicolumn{4}{|l|}{5} \\
\hline 6 & $7.26(\mathrm{~s})$ & $7.28(s)$ & $7.51(\mathrm{~s})$ \\
\hline \multicolumn{4}{|l|}{7} \\
\hline 8 & $7.17(d, 8.0)$ & $7.19(\mathrm{dd}, 7.4,1.0)$ & $7.34(d, 7.8)$ \\
\hline 9 & $7.43(t, 8.0)$ & $7.45(\mathrm{dd}, 7.8,7.3)$ & $7.49(t, 7.8)$ \\
\hline 10 & $7.02(d, 8.0)$ & $7.03(\mathrm{dd}, 7.8,1.0)$ & $6.90(d, 7.8)$ \\
\hline \multicolumn{4}{|l|}{11} \\
\hline \multicolumn{4}{|l|}{12} \\
\hline \multicolumn{4}{|l|}{13} \\
\hline \multicolumn{4}{|l|}{14} \\
\hline \multicolumn{4}{|l|}{15} \\
\hline 16 & $5.73(\mathrm{~s})$ & $5.75(\mathrm{~s})$ & $6.11(\mathrm{~s})$ \\
\hline \multicolumn{4}{|l|}{17} \\
\hline 18 & $5.37(\mathrm{~s})$ & $5.38(\mathrm{~s})$ & $5.56(\mathrm{~s})$ \\
\hline \multicolumn{4}{|l|}{19} \\
\hline 20 & $2.15(\mathrm{~s})$ & $2.15(\mathrm{~s})$ & $2.05(\mathrm{~s})$ \\
\hline 21 & $3.77(\mathrm{~s})$ & $3.77(s)$ & $3.68(\mathrm{~s})$ \\
\hline $\mathrm{OH}$ & $11.38(\mathrm{~s})$ & $11.43(\mathrm{~s})$ & $11.24(\mathrm{~s})$ \\
\hline
\end{tabular}




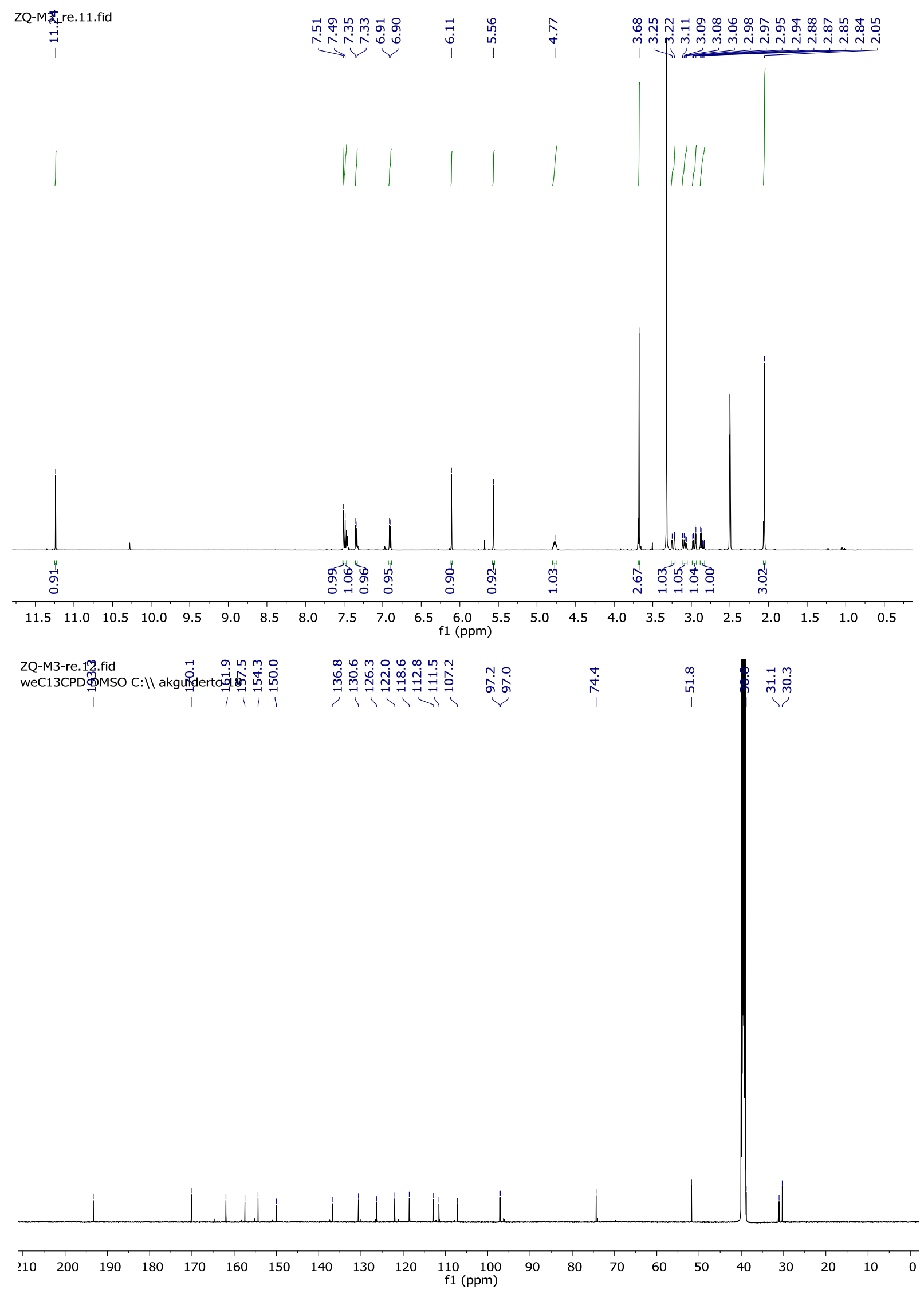

Figure S17. ${ }^{1} \mathrm{H}$ (top) and ${ }^{13} \mathrm{C}-\mathrm{NMR}$ spectra (bottom) of compound $\mathbf{3 a}$. 

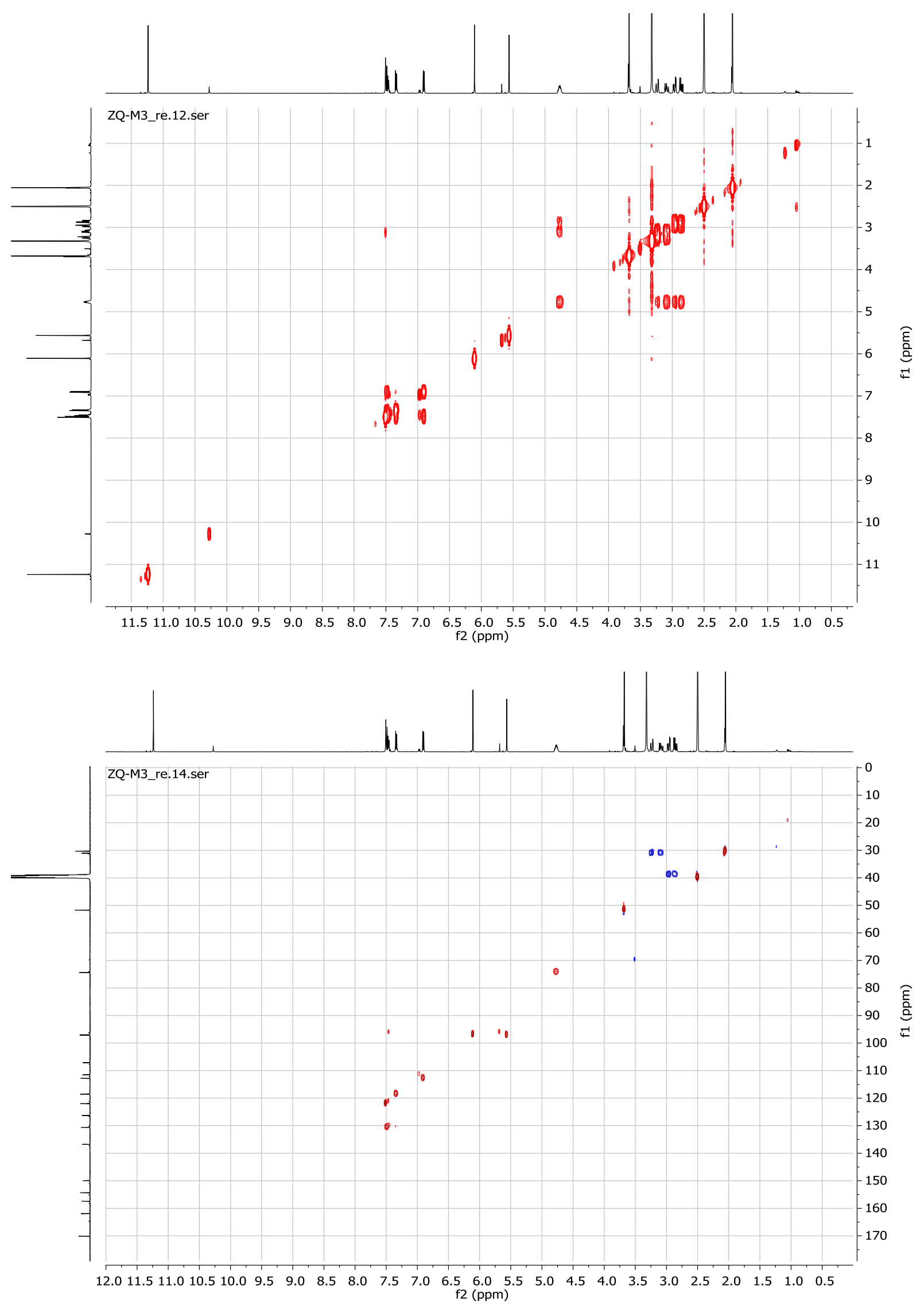

Figure S18. COSY - (top) and HSQC-NMR spectra (bottom) of compound 3a. 


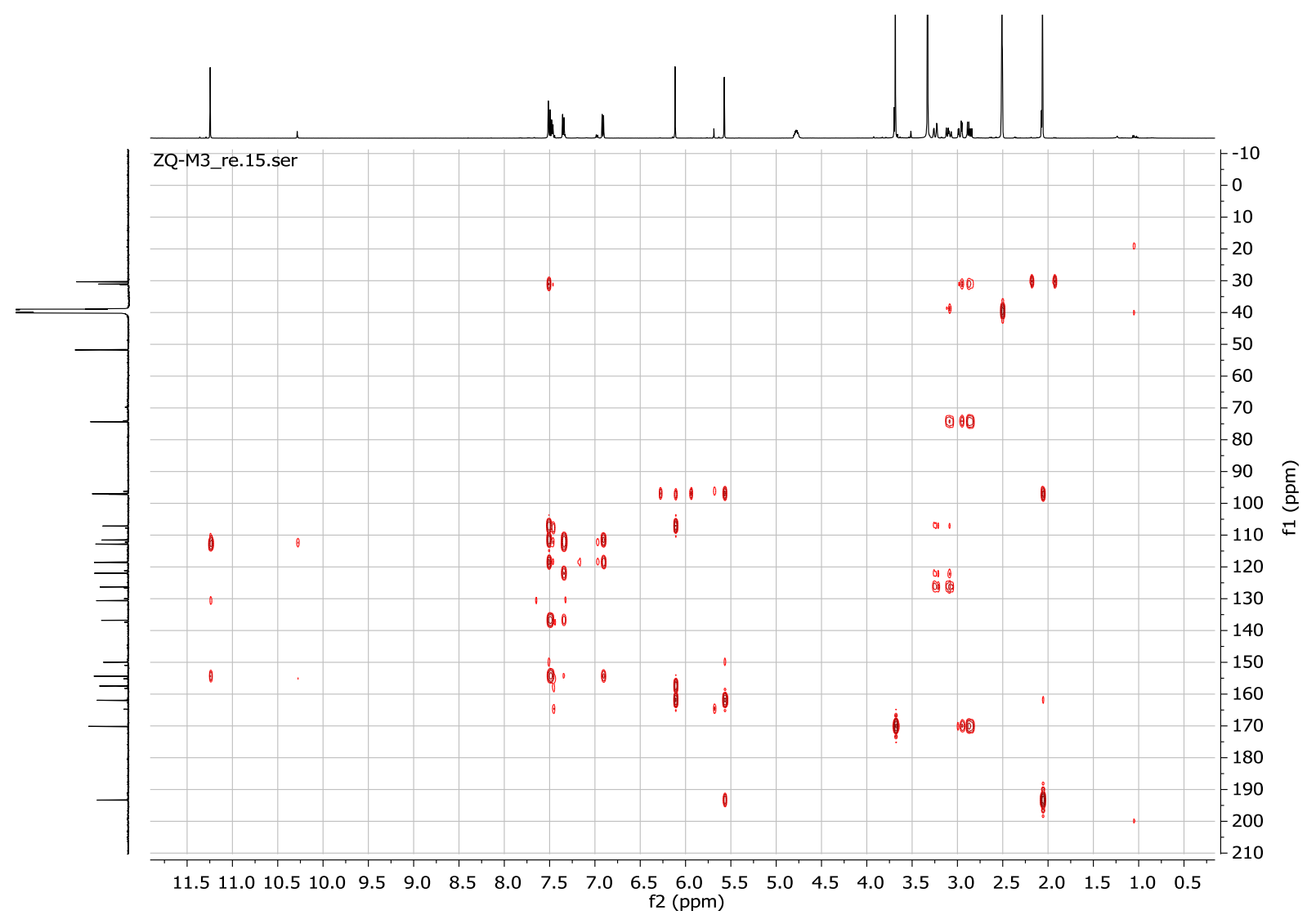

Figure S19. HMBC-NMR spectrum of compound 3a. 

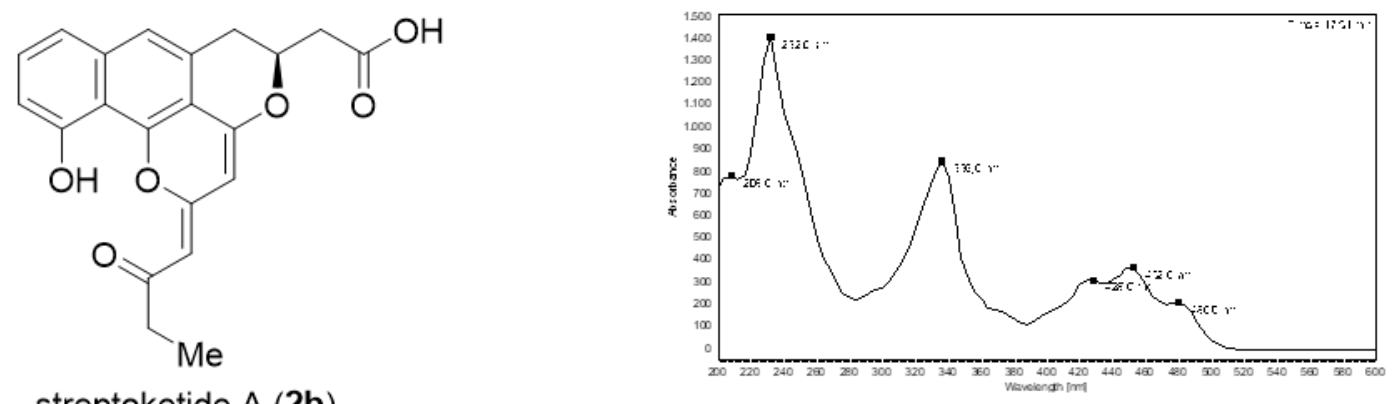

streptoketide A (2b)

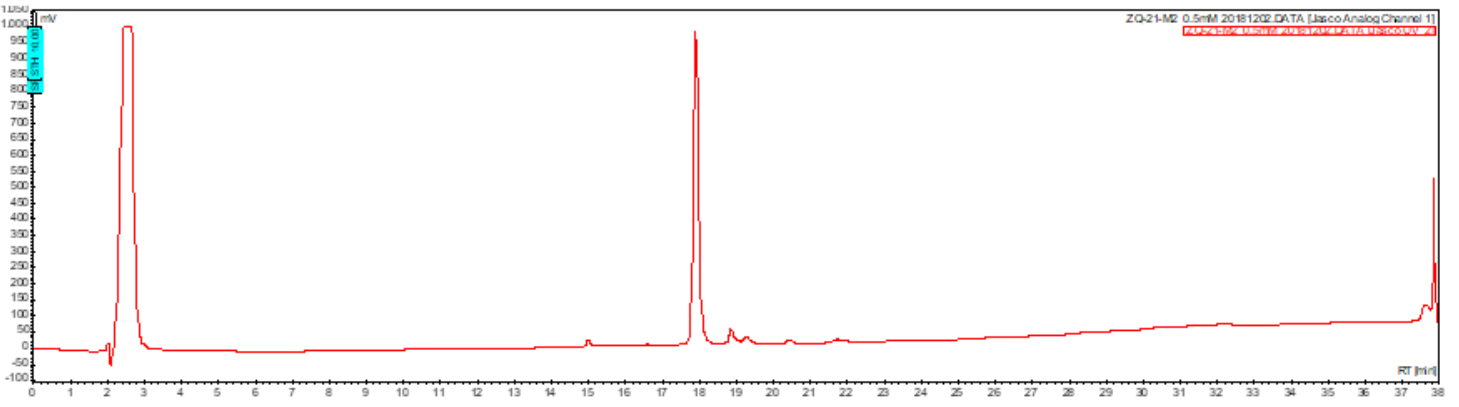

Figure S20. HPLC-UV trace of purified 2b (bottom) and its UV absorption spectrum (top right).

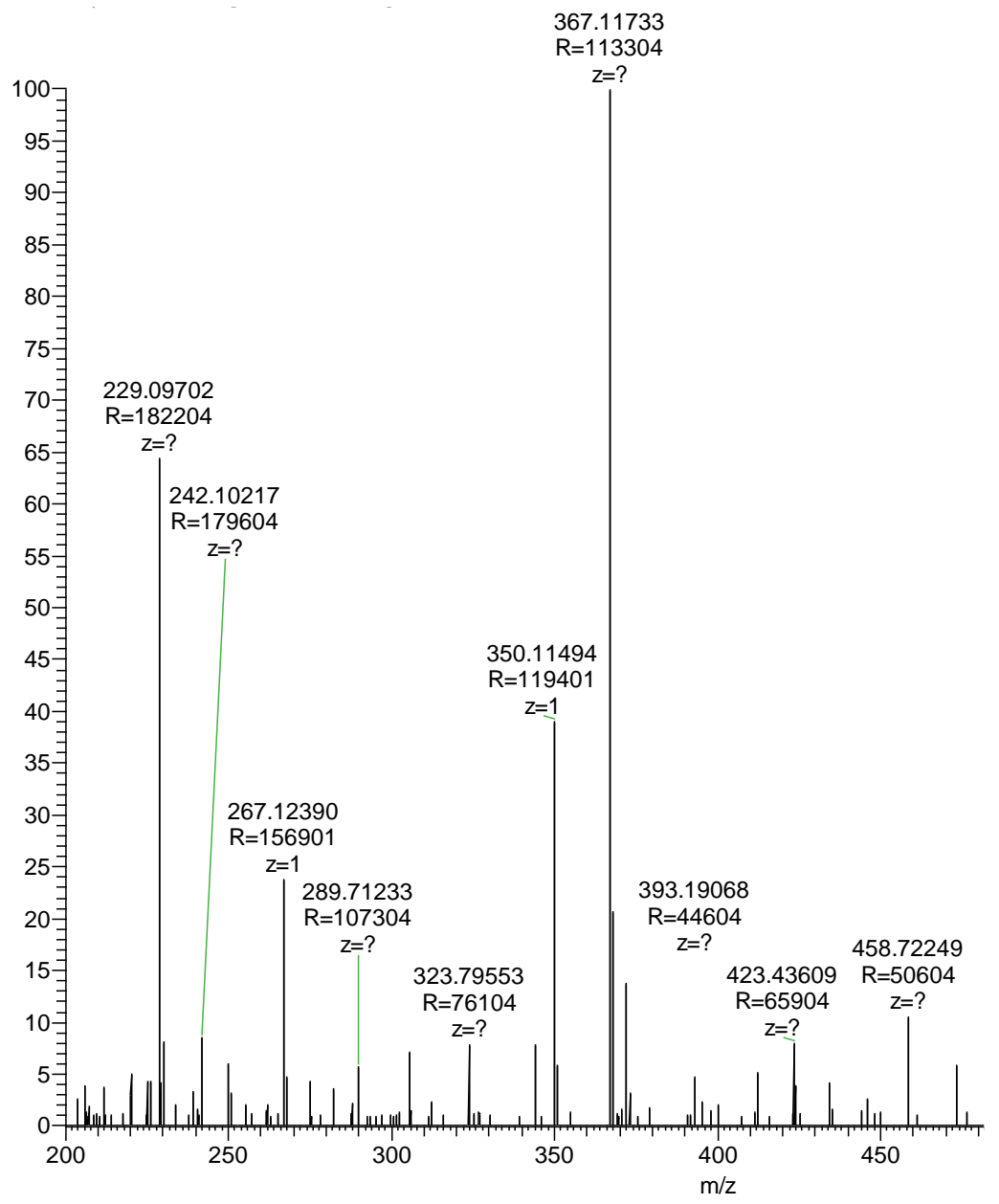

Figure S21. High-resolution ESI-(+) mass spectrum of compound $2 \mathbf{b}$. 

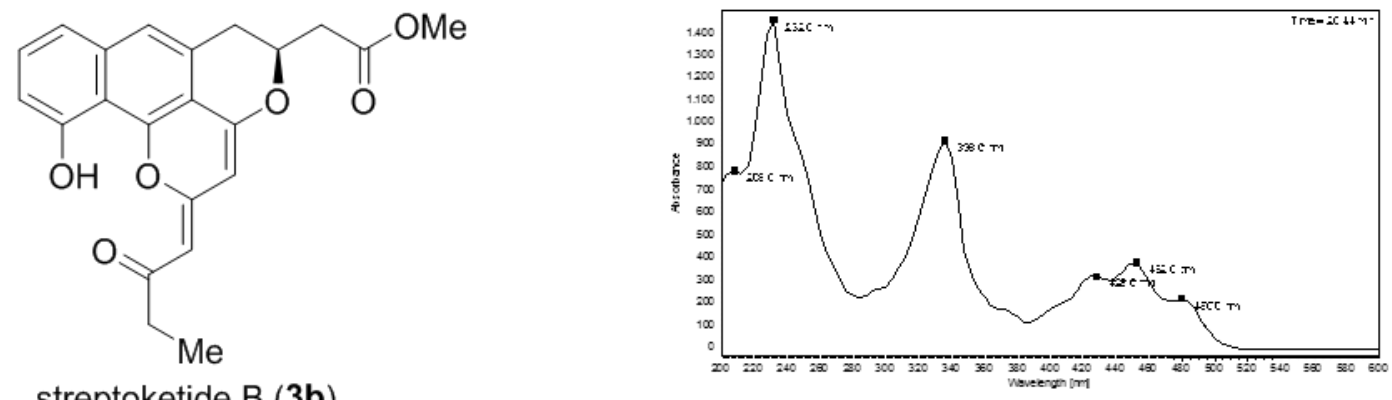

streptoketide B (3b)

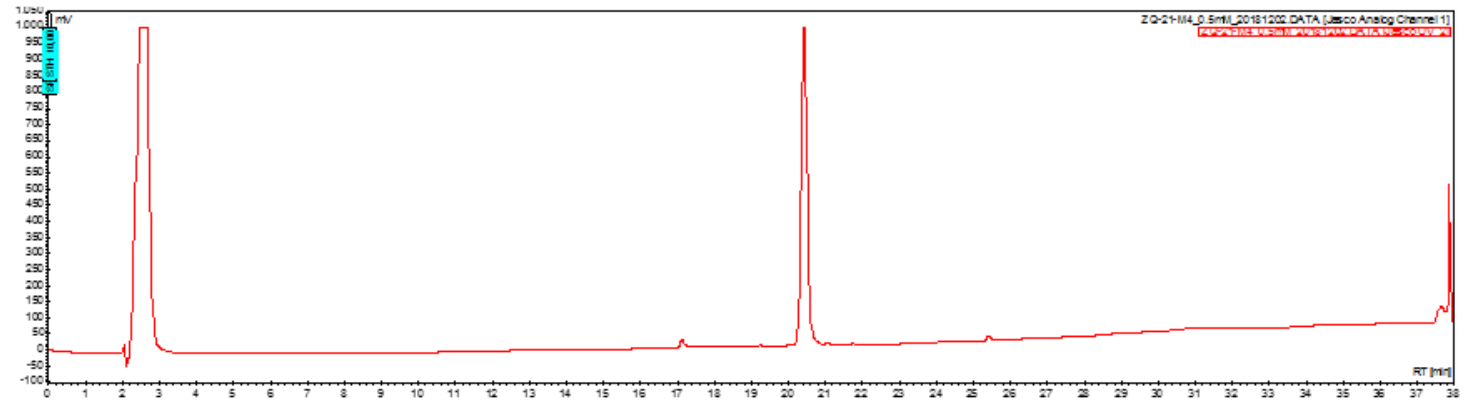

Figure S22. HPLC-UV trace of purified 3b (bottom) and its UV absorption spectrum (top right).

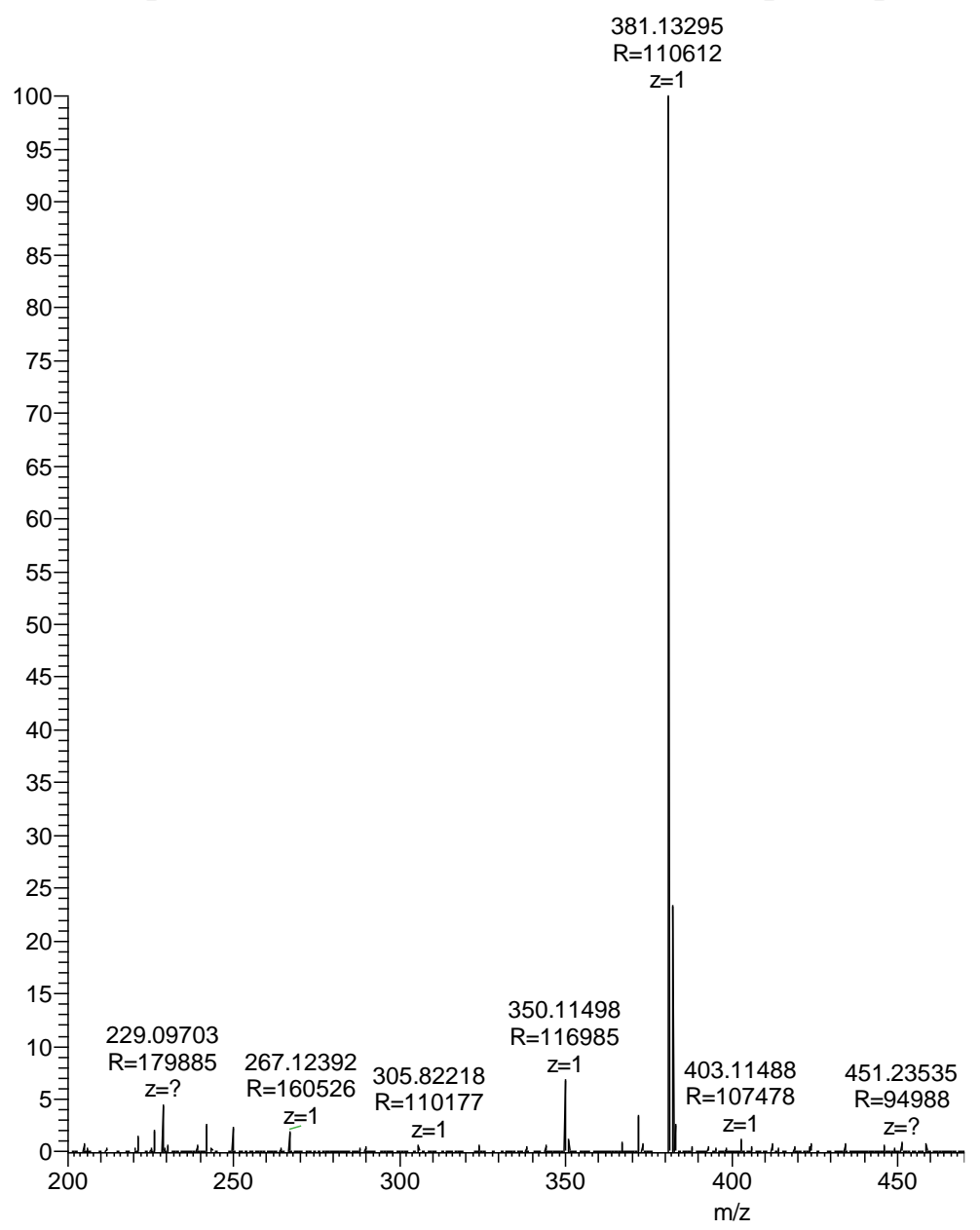

Figure S23. High-resolution ESI-(+) mass spectrum of compound $\mathbf{3 b}$. 
Table S9. ${ }^{1} \mathrm{H}(500 \mathrm{MHz})$ and ${ }^{13} \mathrm{C}(125 \mathrm{MHz}) \mathrm{NMR}$ data of streptoketides A (2b) and B (3b) recorded in DMSO-d 6 .

\begin{tabular}{|c|c|c|c|c|}
\hline Position & ${ }^{13} \mathrm{C}$ of $\mathbf{2} \mathbf{b}$ (acid) & ${ }^{13} \mathrm{C}$ of $\mathbf{3 b}(\mathrm{Me})$ & ${ }^{1} \mathrm{H}$ of $\mathbf{2} \mathbf{b}$ (acid) & ${ }^{1} \mathrm{H}$ of $\mathbf{3 b}(\mathrm{Me})$ \\
\hline 1 & 171.2 & 170.1 & & \\
\hline \multirow{2}{*}{2} & \multirow{2}{*}{ hidden } & \multirow{2}{*}{38.8} & $2.83(\mathrm{dd}, 16.3,5.0)$ & $2.95(d d, 16.3,4.5)$ \\
\hline & & & $2.75(\mathrm{dd}, 16.3,7.8)$ & $2.85(\mathrm{dd}, 16.3,8.2)$ \\
\hline 3 & 74.6 & 74.3 & $4.73(\mathrm{~m})$ & $4.76(\mathrm{~m})$ \\
\hline \multirow{2}{*}{4} & \multirow{2}{*}{31.2} & \multirow{2}{*}{31.1} & $3.24(\mathrm{dd}, 16.6,2.8)$ & $3.22(\mathrm{dd}, 16.7,3.1)$ \\
\hline & & & 3.07 (dd, 16.6, 10.4) & $3.07(\mathrm{dd}, 16.2,10.3)$ \\
\hline 5 & 126.5 & 126.3 & & \\
\hline 6 & 121.9 & 121.9 & $7.51(\mathrm{~s})$ & $7.48(\mathrm{~m})$ \\
\hline 7 & 136.8 & 136.7 & & \\
\hline 8 & 118.6 & 118.5 & $7.34(\mathrm{~d}, 7.9)$ & $7.32(d, 8.0)$ \\
\hline 9 & 130.6 & 130.5 & $7.49(t, 7.9)$ & $7.48(t, 8.0)$ \\
\hline 10 & 112.7 & 112.7 & $6.91(d, 7.9)$ & $6.90(d, 8.0)$ \\
\hline 11 & 154.3 & 154.3 & & \\
\hline 12 & 111.5 & 111.5 & & \\
\hline 13 & 150.0 & 149.9 & & \\
\hline 14 & 107.2 & 107.1 & & \\
\hline 15 & 157.4 & 157.2 & & \\
\hline 16 & 97.0 & 97.1 & $6.11(\mathrm{~s})$ & $6.09(s)$ \\
\hline 17 & 161.9 & 161.8 & & \\
\hline 18 & 96.4 & 96.4 & $5.57(\mathrm{~s})$ & $5.56(s)$ \\
\hline 19 & 196.6 & 196.6 & & \\
\hline 20 & 35.6 & 35.6 & $2.35(q, 7.4)$ & $2.35(q, 7.4)$ \\
\hline 21 & 9.3 & 9.3 & $1.02(t, 7.4)$ & $1.02(t, 7.4)$ \\
\hline 22 (OMe) & - & 51.8 & - & $3.68(s)$ \\
\hline $\mathrm{OH}$ & - & - & 11.29 & 11.27 \\
\hline
\end{tabular}




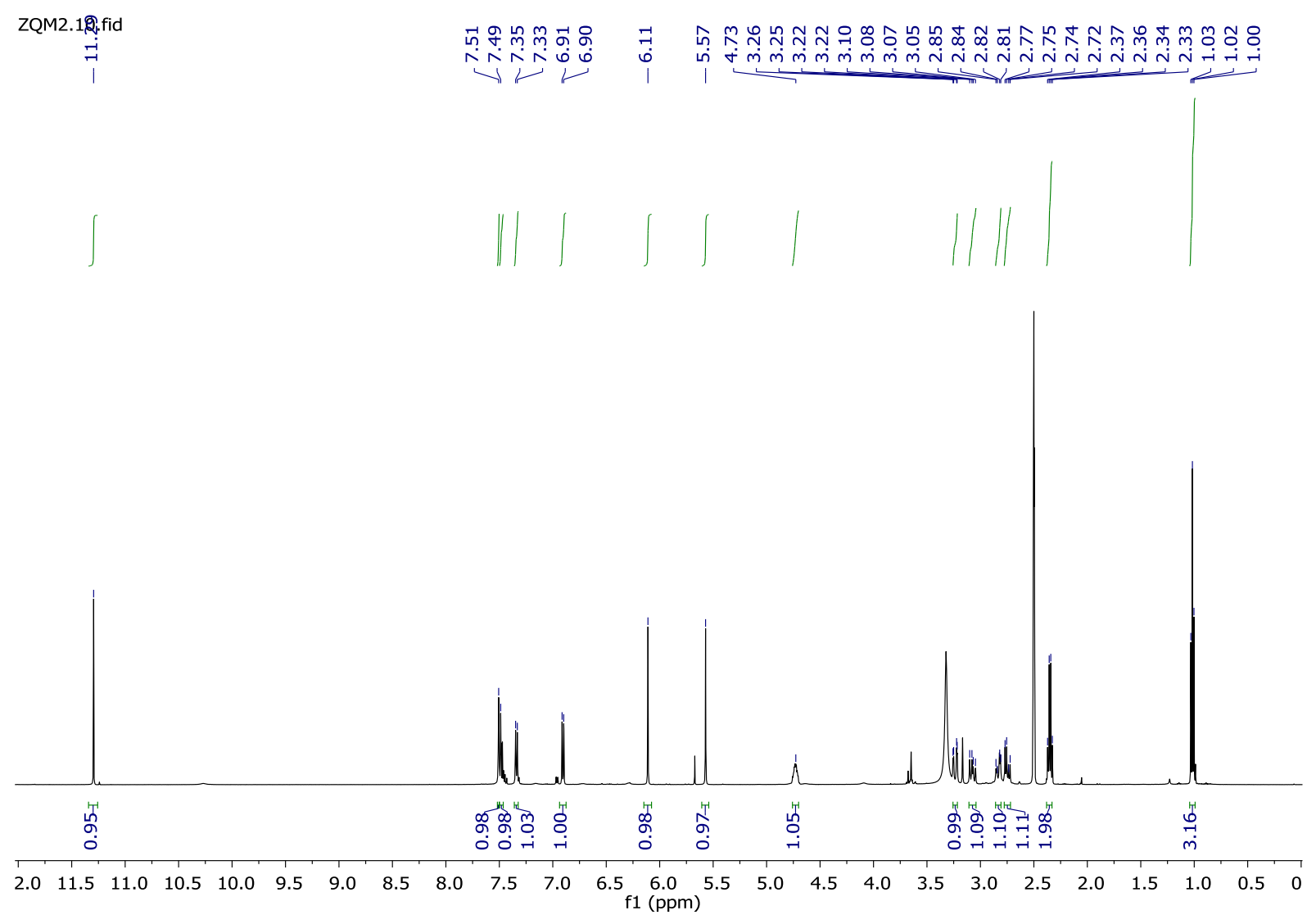

ZQ-NQ2_re.12.fid N

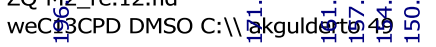

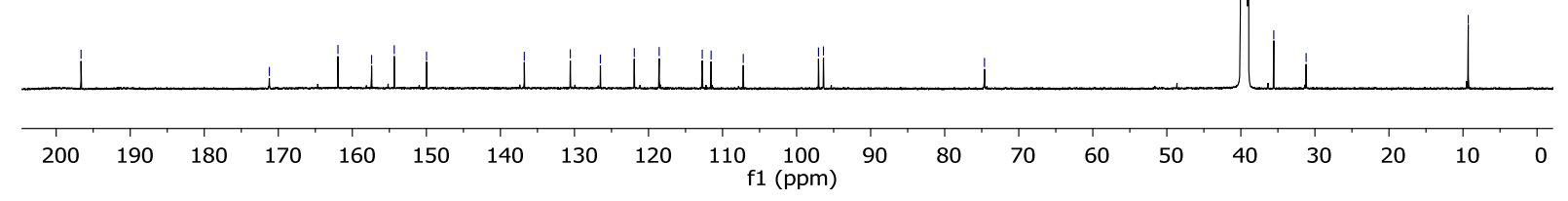

Figure S24. ${ }^{1} \mathrm{H}$ (top) and ${ }^{13} \mathrm{C}-\mathrm{NMR}$ spectra (bottom) of compound $\mathbf{2 b}$. 


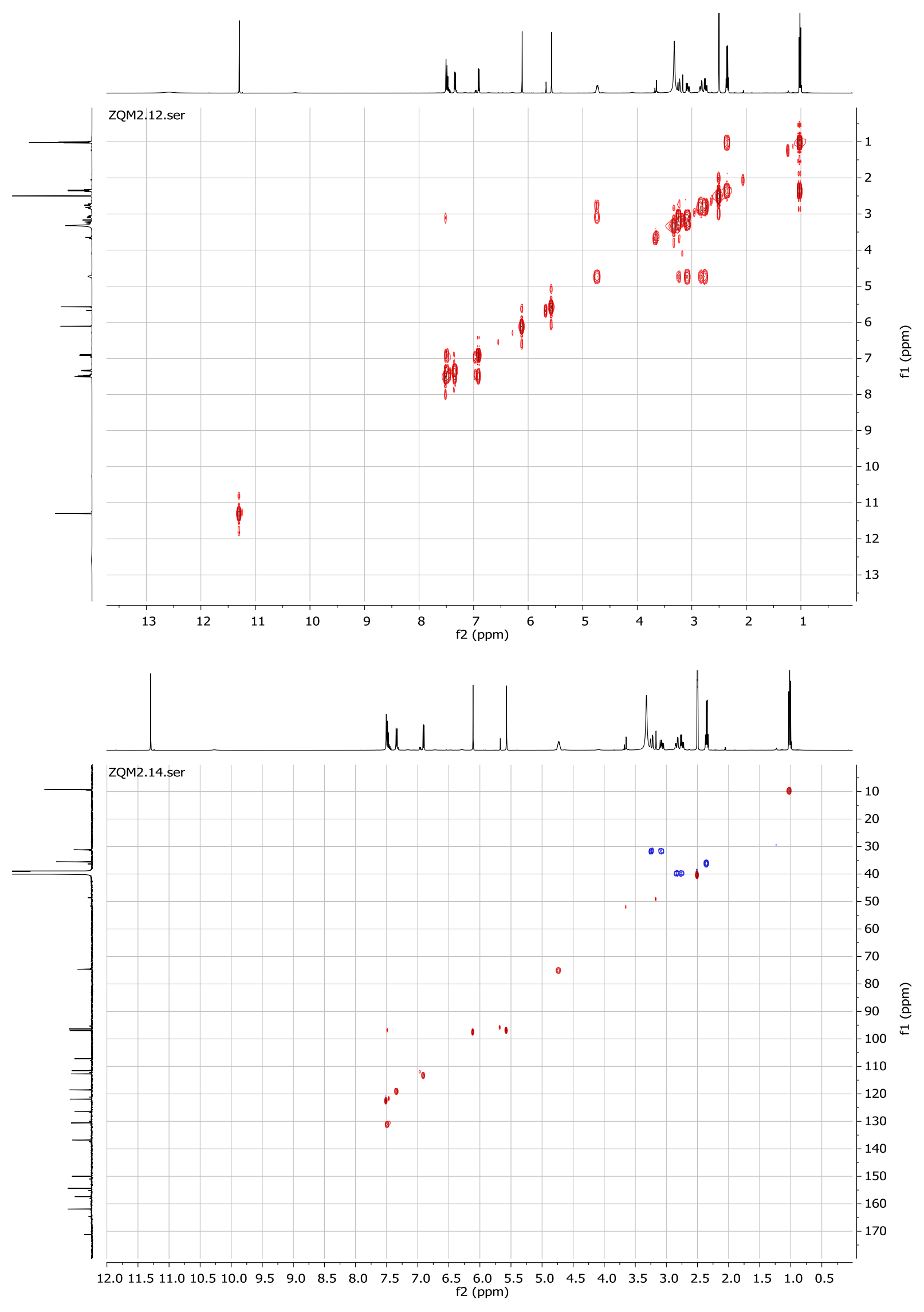

Figure S25. COSY - (top) and HSQC-NMR spectra (bottom) of compound $\mathbf{2 b}$. 


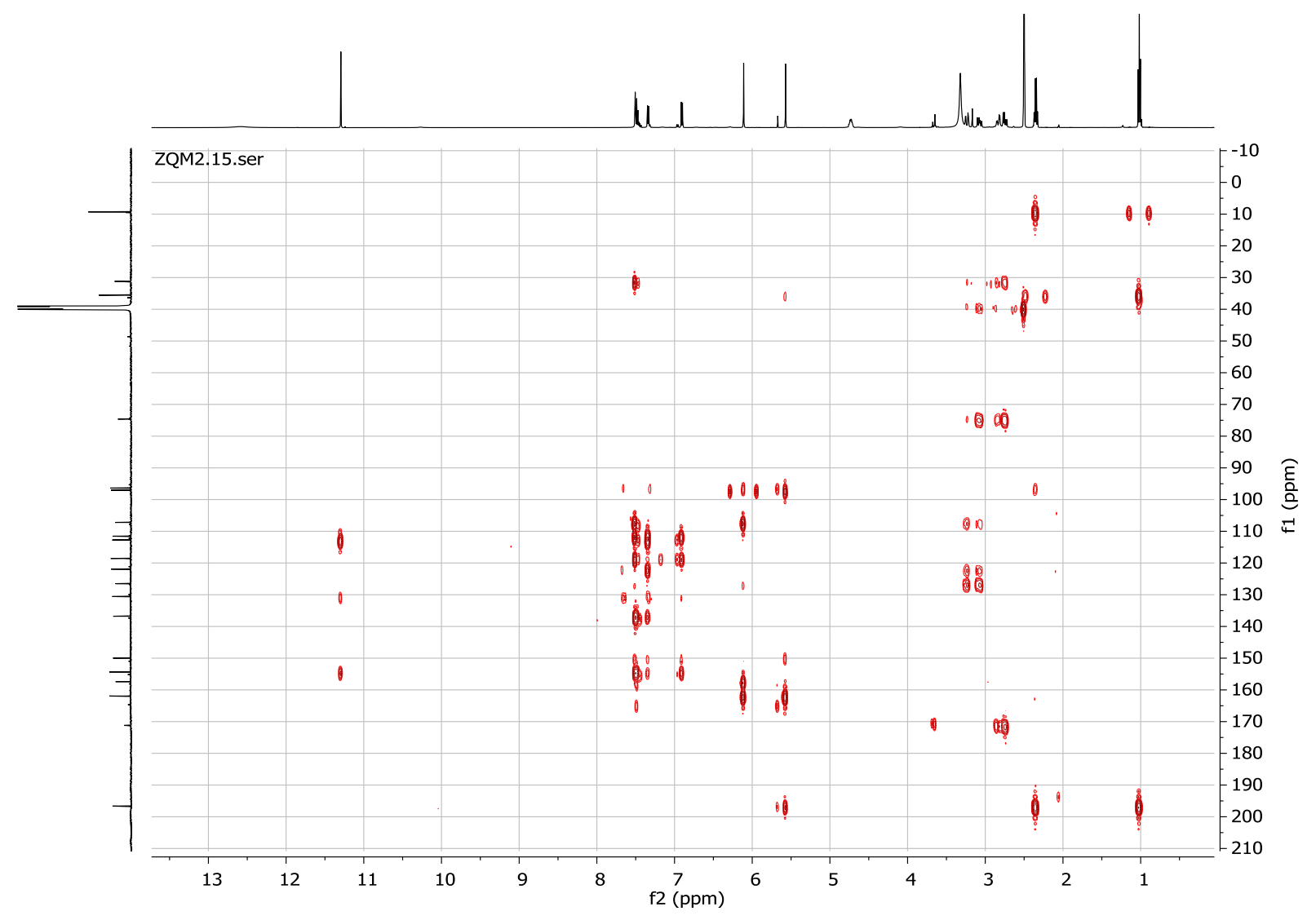

Figure S26. HMBC-NMR spectrum of compound $2 \mathbf{b}$. 


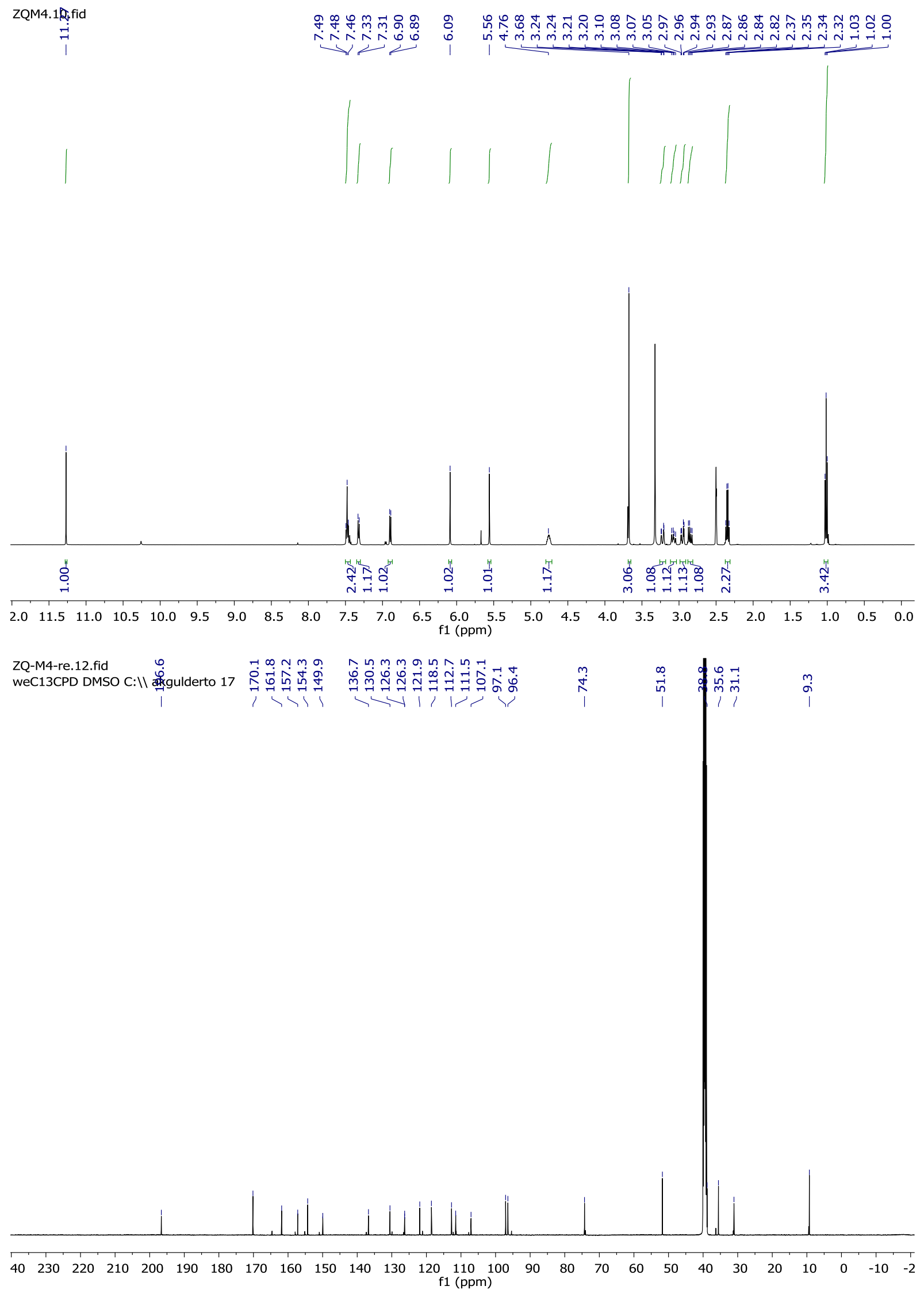

Figure S27. ${ }^{1} \mathrm{H}$ (top) and ${ }^{13} \mathrm{C}-\mathrm{NMR}$ spectra (bottom) of compound $\mathbf{3 b}$. 

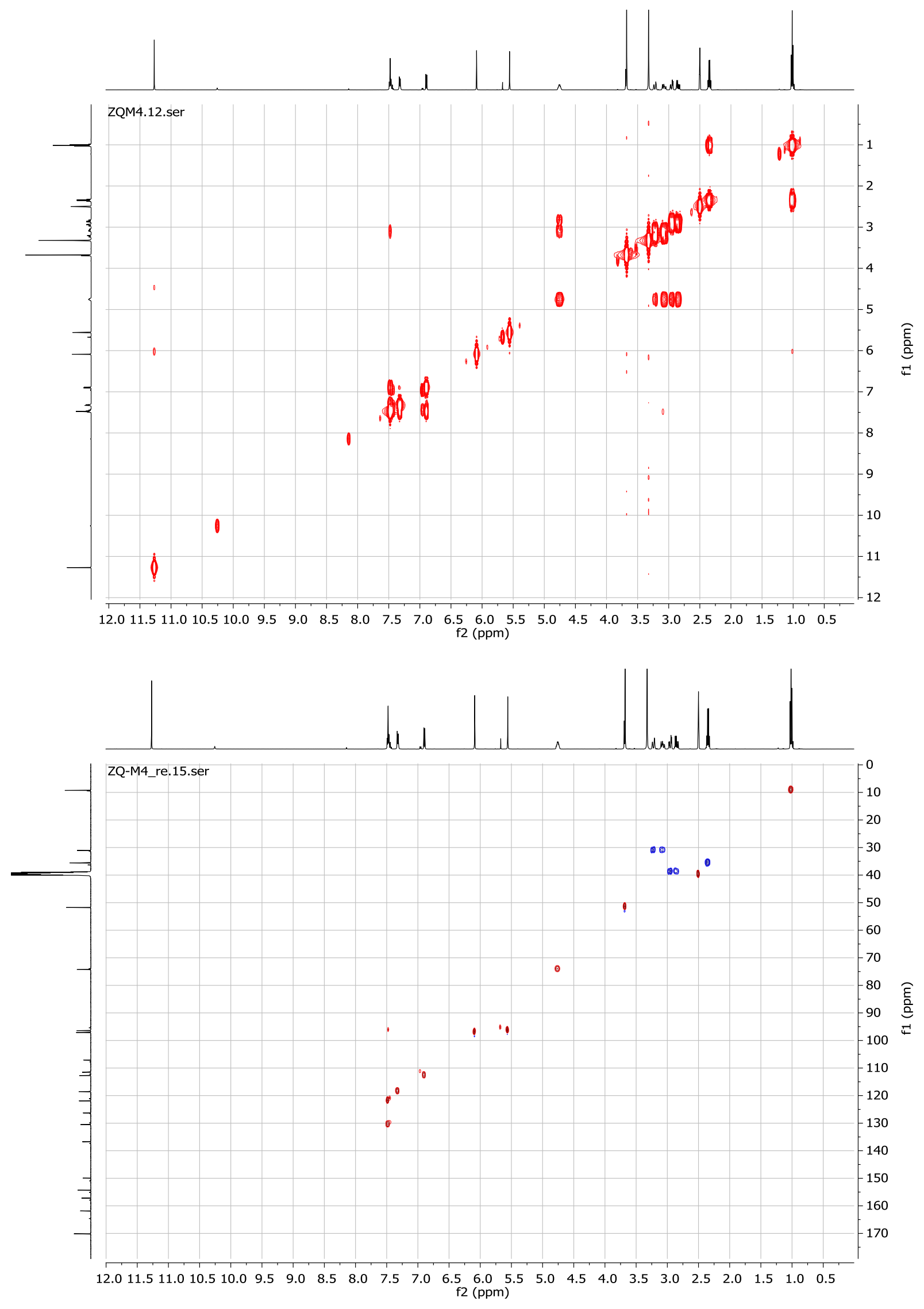

Figure S28. COSY - (top) and HSQC-NMR spectra (bottom) of compound $\mathbf{3 b}$. 


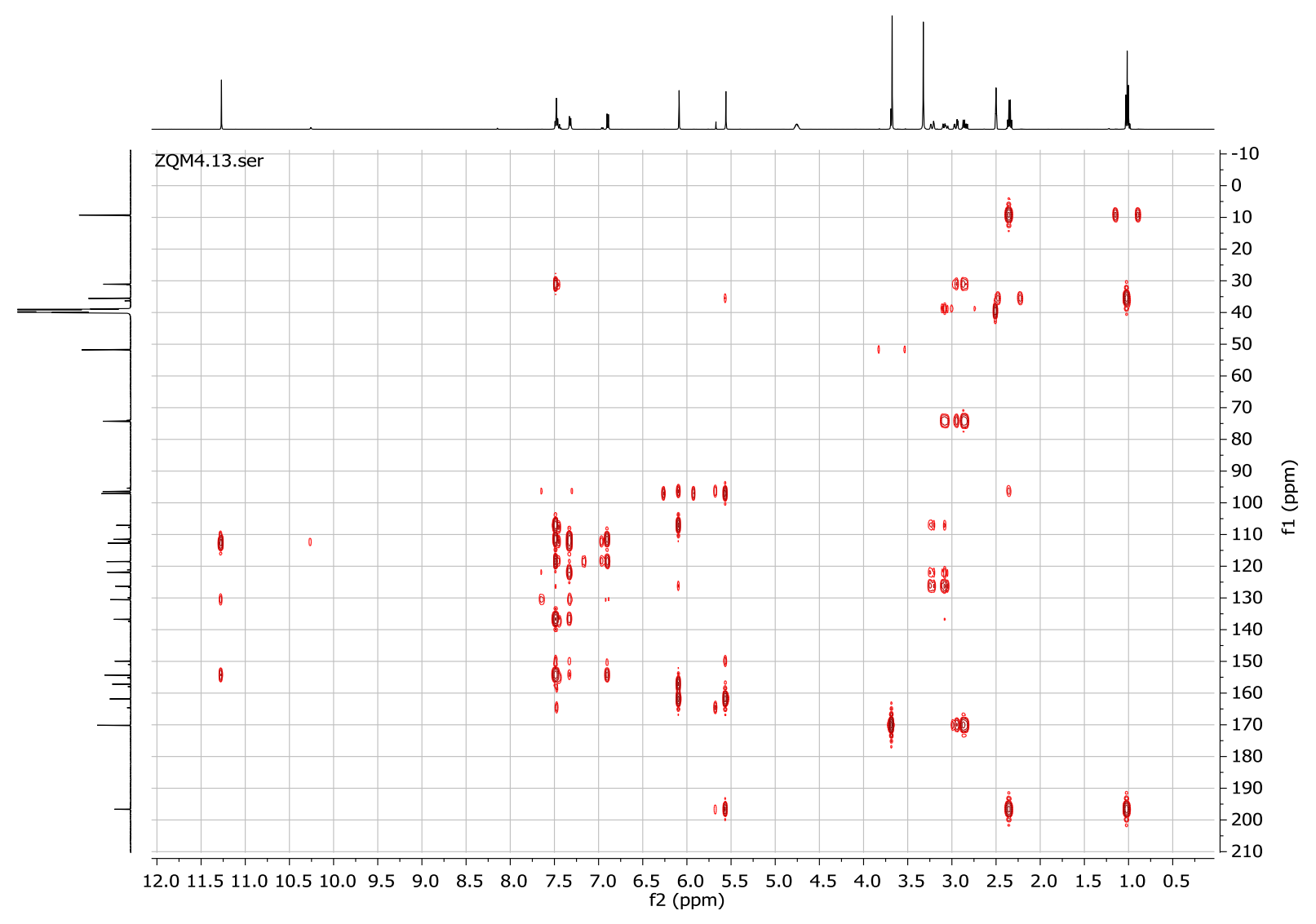

Figure S29. HMBC-NMR spectrum of compound 3b. 
<smiles>O=C(O)CC1Cc2cc3cccc(O)c3c(O)c2C(=O)O1</smiles>
streptoketide C (4)
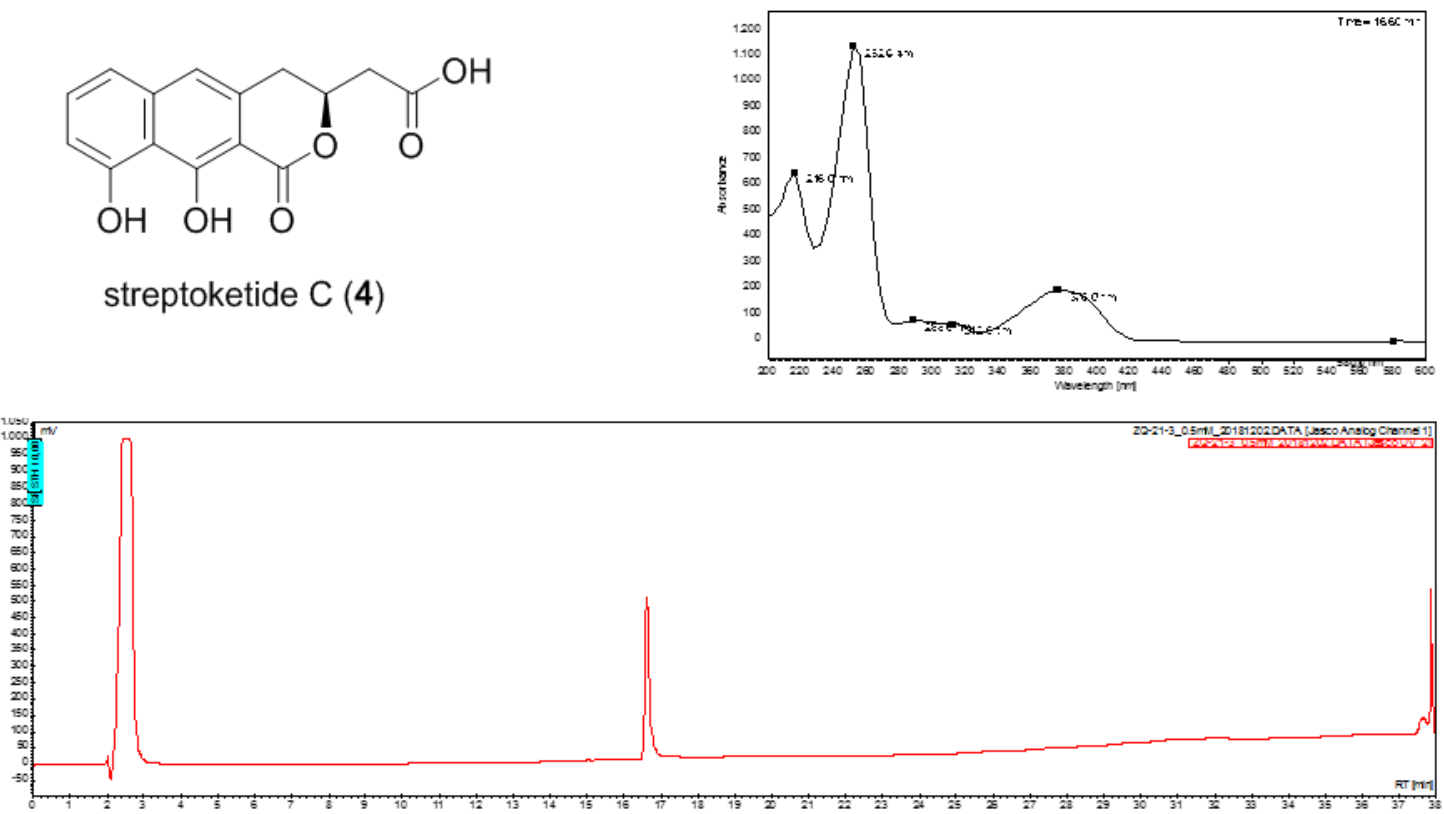

Figure S30. HPLC-UV trace of purified 4 (bottom) and its UV absorption spectrum (top right).

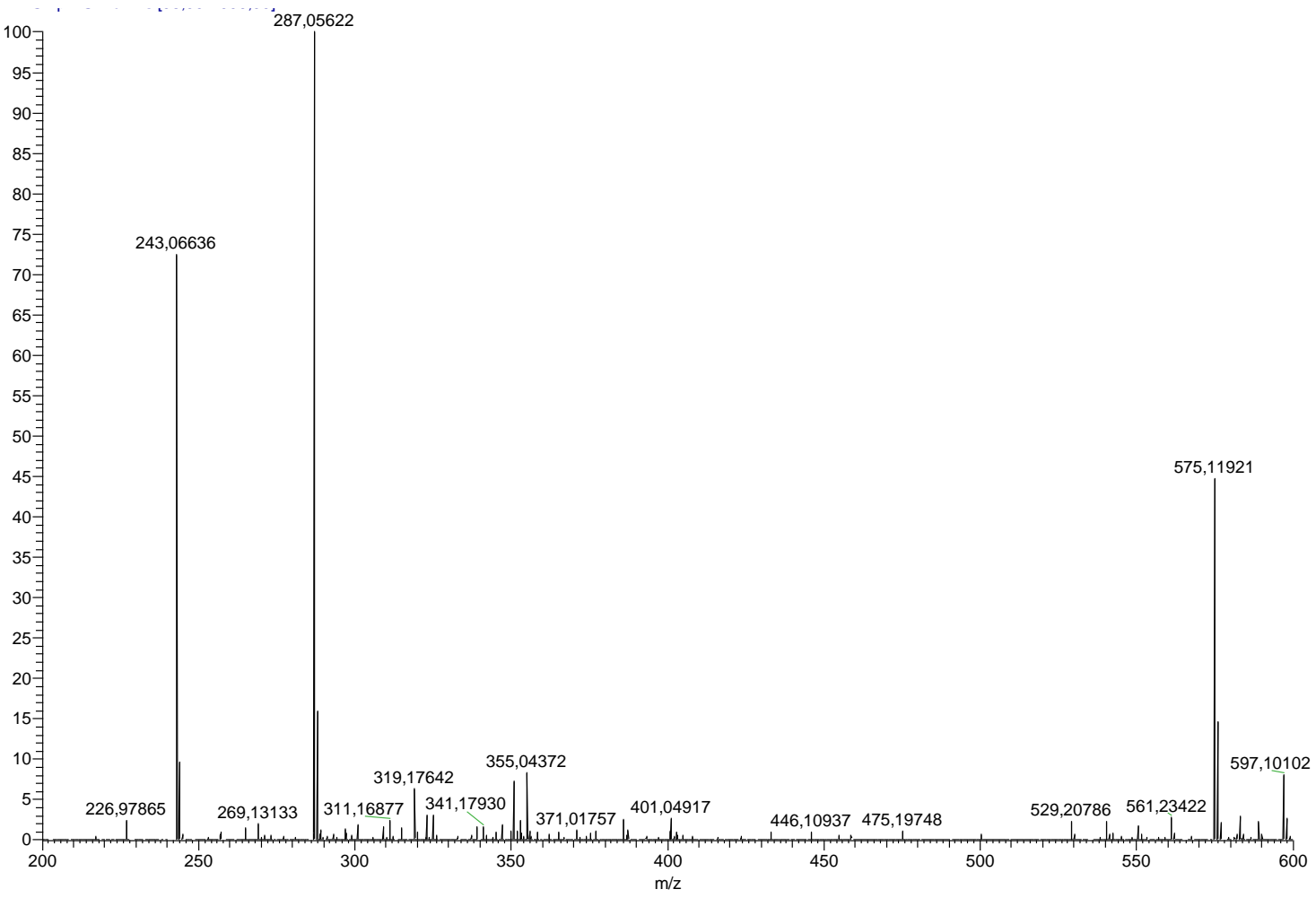

Figure S31. High-resolution ESI-(+) mass spectrum of compound 4. 


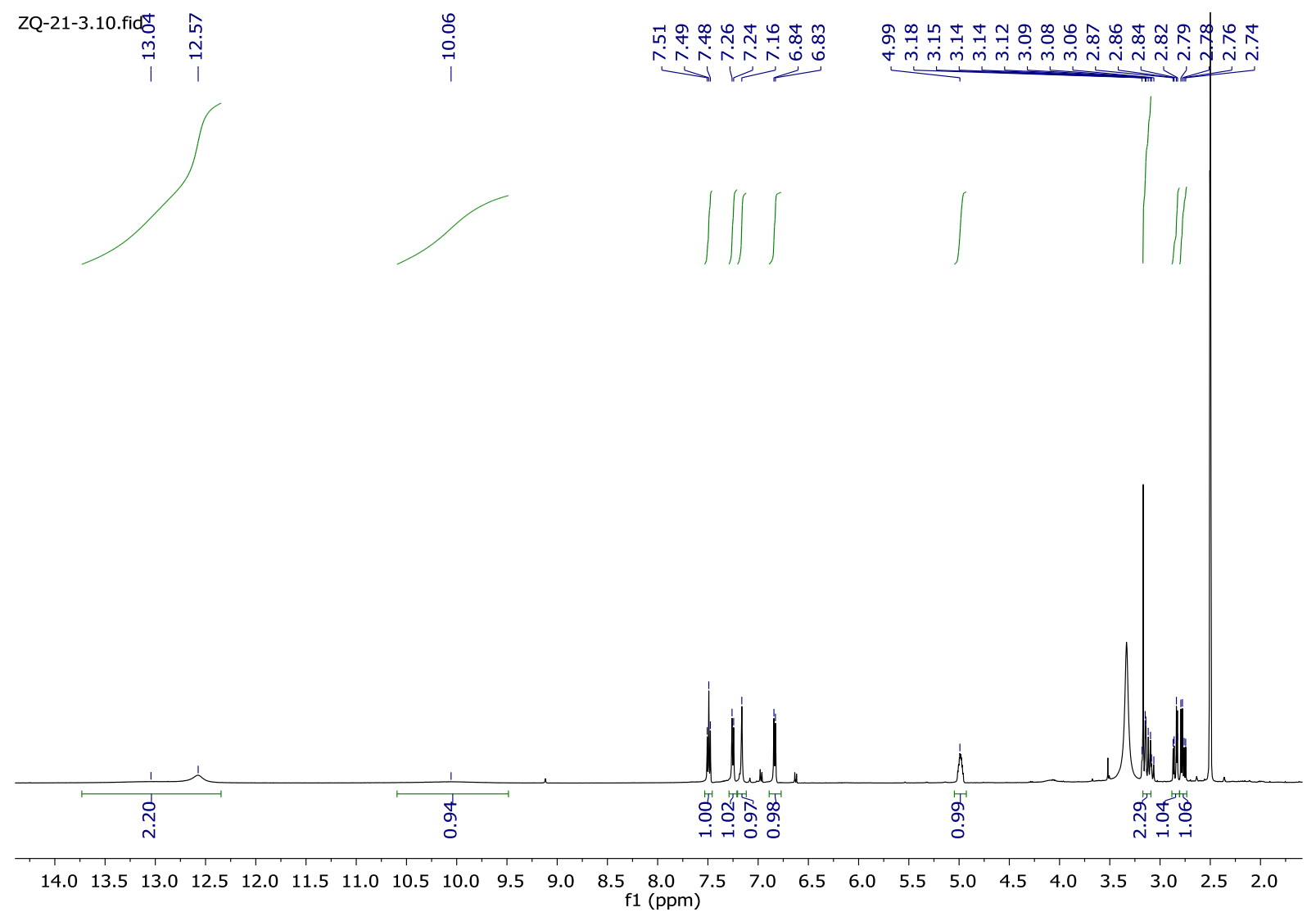

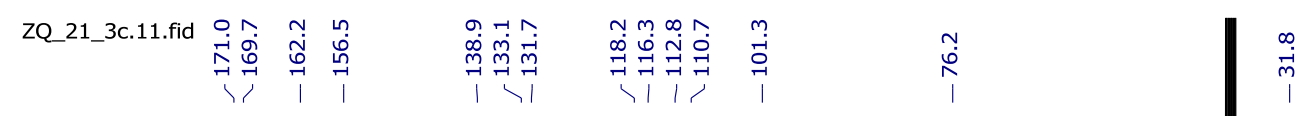

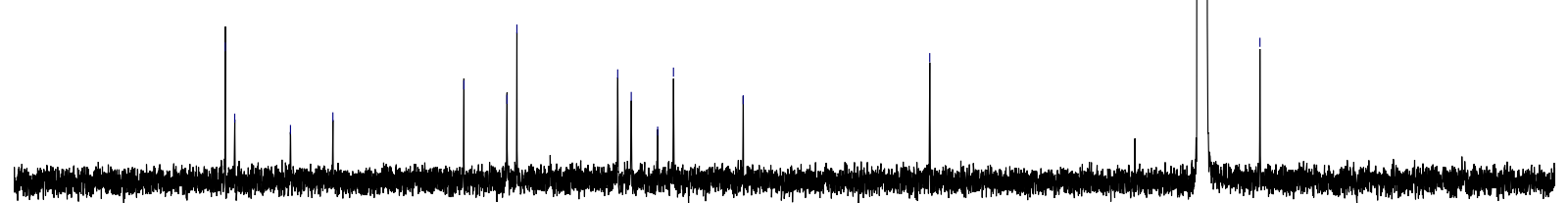

$\begin{array}{llllllllllllllllllllll}190 & 180 & 170 & 160 & 150 & 140 & 130 & 120 & 110 & 100 & 90 & 80 & 70 & 60 & 50 & 40 & 30 & 20 & 10 & 0 & \end{array}$

Figure S32. ${ }^{1} \mathrm{H}$ (top) and ${ }^{13} \mathrm{C}-\mathrm{NMR}$ spectra (bottom) of compound 4. 

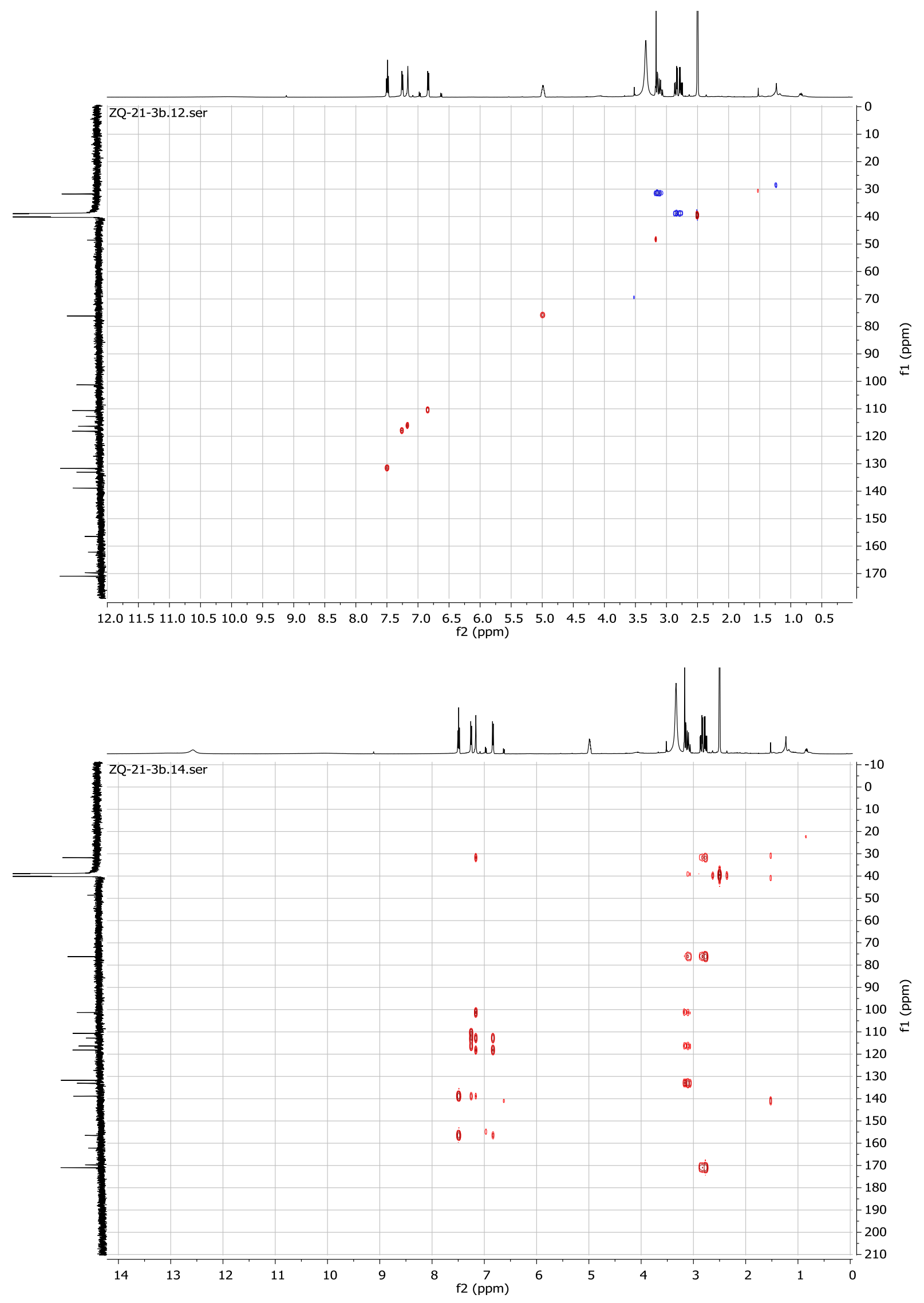

Figure S33. HSQC (top) and HMBC-NMR spectra (bottom) of compound 4. 


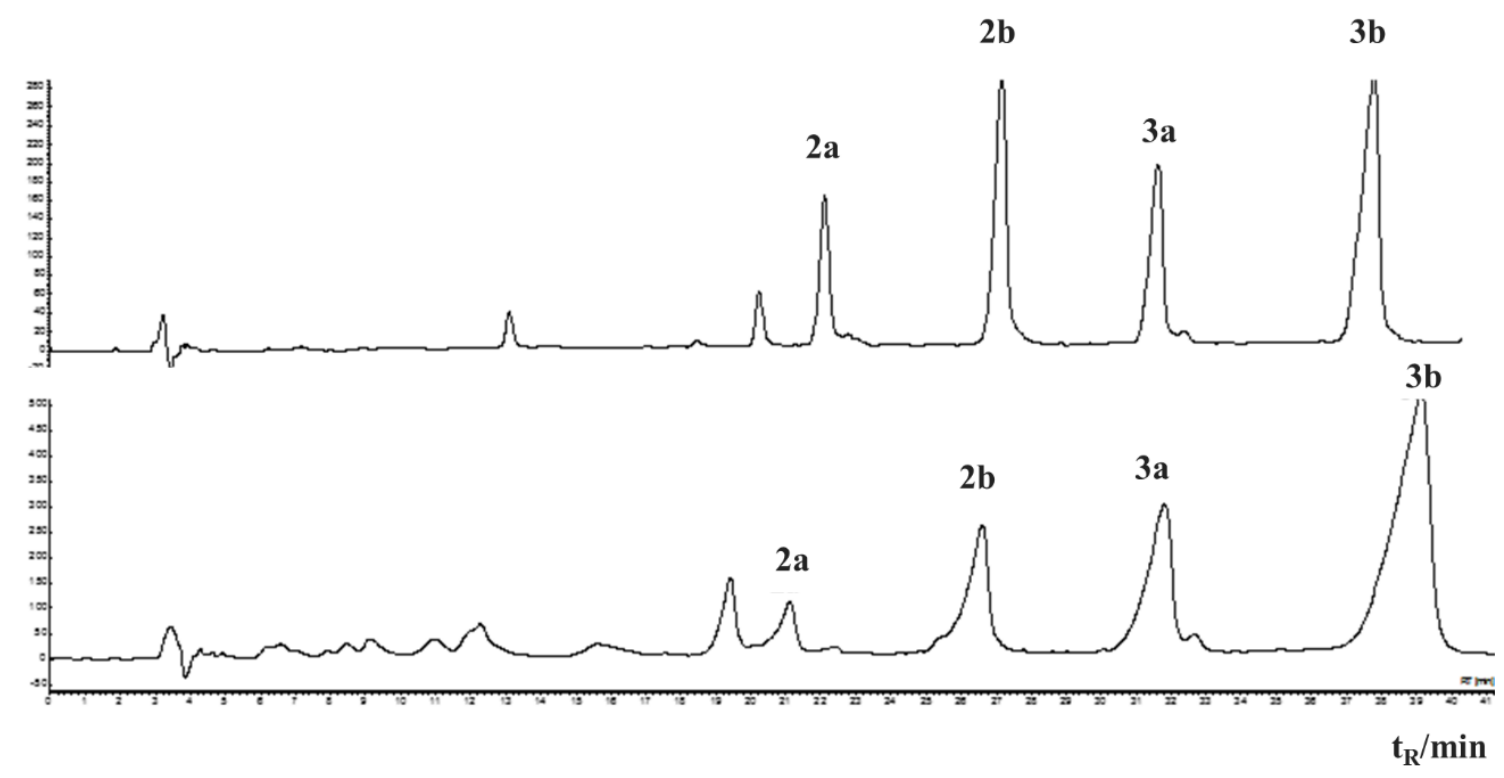

Figure S34. The compound ratio between acids $\mathbf{2 a} / \mathbf{b}$ and methyl esters $\mathbf{3 a} / \mathbf{b}$ changes over time upon standing in MeOH. Top: HPLC-UV trace of compound mixture directly after injection. Bottom: HPLC-UV trace several hours after dissolving extract in $\mathrm{MeOH}$. The amount of $\mathbf{3 a} / \mathbf{b}$ increases, while $\mathbf{2} \mathbf{a} / \mathbf{b}$ content drops, pointing at a non-enzymatic esterification reaction. 
Heat of formation (B3LYP/def2-TZVP), number of imaginary frequencies, and cartesian coordinates of the equatorial and the axial conformation of $\mathbf{3 a}$.

3a (equatorial), Heat of Formation: -1262.298918310823 Eh

No imaginary frequencies

\begin{tabular}{|c|c|c|c|}
\hline & -18.69634544813687 & 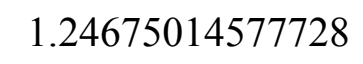 & \\
\hline & & & \\
\hline & 7.54471810005603 & 494 & \\
\hline & 11680621 & & \\
\hline & 2373 & & \\
\hline & 073 & & \\
\hline & 5.02129472070770 & -0.86 & \\
\hline & 935 & & \\
\hline & & & \\
\hline & 12 & & \\
\hline & 22 & -0.8 & \\
\hline & -11. & -0.1 & \\
\hline & -11. & & \\
\hline & 65 & 1.9 & \\
\hline & -14 & & \\
\hline & 74 & -2.9 & \\
\hline C & -12 . & & \\
\hline ) & -14 & -6.4 & \\
\hline C & -14 & -5.3 & \\
\hline$y$ & -13. & -4 & \\
\hline & -17 & -2.1 & \\
\hline$y$ & -10 & & \\
\hline & -9.9 & 3.16 & \\
\hline $\mathrm{O}$ & -9.4 & 4.0 & \\
\hline O & -10 & & \\
\hline C & -10. & 4.71 & \\
\hline & -16 & & \\
\hline $\mathrm{H}$ & -19 . & & \\
\hline I & -19 . & -0.6 & \\
\hline & -17 . & & \\
\hline $\mathrm{H}$ & -15 . & 2.9 & \\
\hline H & -11. & & \\
\hline $\mathrm{H}$ & -12 & & \\
\hline H & -12.5 & & \\
\hline $\mathrm{H}$ & -11. & -2.7 & \\
\hline $\mathrm{H}$ & -12 & -4.7 & \\
\hline $\mathrm{H}$ & -16. & -2.60 & \\
\hline $\mathrm{H}$ & -9.7 & 1.64 & \\
\hline $\mathrm{H}$ & -9.36 & 1.111 & \\
\hline $\mathrm{H}$ & -10.6 & 1967 & \\
\hline & -10.8 & 38047 & \\
\hline $\mathrm{H}$ & -9.21066 & 5.036 & -2.1 \\
\hline & -16.7916009 & -5.880 & 0.8 \\
\hline & -16.3665094 & -4.20 & 1.236005 \\
\hline & -16.86075931958 & -4.6389531804523 & -0.411382 \\
\hline
\end{tabular}


3a (axial), not used for the ECD calculation, Heat of Formation: $-1262.299055406826 \mathrm{Eh}$

No imaginary frequencies

\begin{tabular}{|c|c|c|c|}
\hline $\mathrm{C}$ & -19.06350660626086 & 1.00219264149527 & 0.60708977062272 \\
\hline $\mathrm{C}$ & -19.08157144146503 & -0.38983419285334 & 0.46687190833326 \\
\hline $\mathrm{C}$ & -17.91007030067547 & -1.09610755957650 & 0.29430809616351 \\
\hline $\mathrm{C}$ & -16.65415543957643 & -0.41653247281669 & 0.26698129267402 \\
\hline $\mathrm{C}$ & -16.65859869374659 & 1.01489985511192 & 0.38685936865277 \\
\hline $\mathrm{C}$ & -17.87968573456393 & 1.69623594953923 & 0.56589919029250 \\
\hline $\mathrm{C}$ & -15.39103678687371 & -1.04682464561119 & 0.10595495167376 \\
\hline $\mathrm{C}$ & -14.22752063110107 & -0.31061184050073 & -0.01852941057215 \\
\hline $\mathrm{C}$ & -14.25177713607346 & 1.10515228546673 & 0.06727784655544 \\
\hline $\mathrm{C}$ & -15.43975915205710 & 1.73478650720068 & 0.29777775091484 \\
\hline $\mathrm{C}$ & -12.99376557300051 & -1.01706417523933 & -0.26028173807424 \\
\hline $\mathrm{O}$ & -11.85308146681830 & -0.32106949514169 & -0.46455596408068 \\
\hline $\mathrm{C}$ & -11.75342660074146 & 0.96444192592982 & 0.19835900323292 \\
\hline $\mathrm{C}$ & -12.95328766182520 & 1.83298037457156 & -0.15395453538385 \\
\hline $\mathrm{O}$ & -15.35376190801211 & -2.42194495326998 & 0.05761451105583 \\
\hline $\mathrm{C}$ & -14.16956635423957 & -3.13023217054735 & 5148653536 \\
\hline $\mathrm{C}$ & -12.98006085534861 & -2.36660347121158 & -0.30930015011837 \\
\hline $\mathrm{O}$ & -14.80622186300747 & $-6.684^{\prime}$ & 0.29109384489091 \\
\hline $\mathrm{C}$ & -15.13463246603299 & -5.50515662178398 & 0.32082097422235 \\
\hline $\mathrm{C}$ & -14.14608458273283 & -4.48896157348711 & -0.02044514865627 \\
\hline $\mathrm{O}$ & -18.02117326976268 & -2.43174334927577 & 0.13358419426791 \\
\hline $\mathrm{C}$ & -11.54294788404168 & 0.71233150574619 & 1.69029775307034 \\
\hline $\mathrm{C}$ & -10.96267494166881 & 1.90045277208588 & 2.42033758039769 \\
\hline $\mathrm{O}$ & 405926728564 & & 176152887 \\
\hline $\mathrm{O}$ & -10.36989429688913 & 1.51004949095068 & 3.55959774434184 \\
\hline $\mathrm{C}$ & -9.77258399811374 & 2.54331473812893 & 4.36215565268919 \\
\hline $\mathrm{C}$ & -16.54264217625260 & -5.14145693135655 & 0.73359664054501 \\
\hline $\mathrm{H}$ & -19.99809598486560 & 1.53132433512597 & 0.74203284092799 \\
\hline $\mathrm{H}$ & -20.01009213132999 & -0.94412559217157 & 0.48084633200859 \\
\hline $\mathrm{H}$ & -17.86520612295478 & 2.77399110217995 & 0.66364001655273 \\
\hline $\mathrm{H}$ & -15.47319276039046 & 2.81384694338182 & 0.39201363783740 \\
\hline $\mathrm{H}$ & -10.85041615544600 & 1.40329746671064 & -0.22127788648991 \\
\hline $\mathrm{H}$ & -12.90941251035991 & 2.75598133401473 & 0.42153489820521 \\
\hline $\mathrm{H}$ & -12.87369962410396 & 2.10758407876253 & -1.21036342553946 \\
\hline $\mathrm{H}$ & -12.05477353821407 & -2.90006209728544 & -0.46605067506256 \\
\hline $\mathrm{H}$ & -13.17266677604097 & -4.92042454521555 & -0.21598884623397 \\
\hline $\mathrm{H}$ & -17.14314047899950 & -2.82742022227366 & 0.04224449146697 \\
\hline $\mathrm{H}$ & -12.48360769117846 & 0.43933350809080 & 2.17807051937138 \\
\hline $\mathrm{H}$ & -10.87162118369212 & -0.13704075335411 & 1.81695575002949 \\
\hline $\mathrm{H}$ & -9.07223291009682 & 3.12753053442127 & 3.76695216078675 \\
\hline $\mathrm{H}$ & -10.54149967573671 & 3.20308331890625 & 4.76318171413521 \\
\hline $\mathrm{H}$ & -9.25745860129506 & 2.02392107830257 & 5.16515054856048 \\
\hline $\mathrm{H}$ & -16.99787017509141 & -6.01315399202089 & 1.19878784349143 \\
\hline $\mathrm{H}$ & -16.56850254648506 & -4.30349819694674 & 1.42945272547673 \\
\hline $\mathrm{H}$ & -17.13571404555213 & -4.88236382449021 & -0.14714404822922 \\
\hline
\end{tabular}


Heat of formation and Gibbs free enthalpy (B3LYP/def2-TZVP), number of imaginary frequencies, and cartesian coordinates of the equatorial and the axial conformation of 4 .

$4_{\text {equ }}$

Heat of Formation: -1030.156703967375 Eh

Gibbs Free Enthalpy: -1029.94901907 Eh

No imaginary frequencies

$\begin{array}{llcc}\mathrm{C} & -11.69238114677195 & 0.76783776601595 & 0.44952621214811 \\ \mathrm{C} & -11.81388881287684 & -0.64335443308506 & 0.24743784449737 \\ \mathrm{C} & -13.10675466117885 & -1.21861262218924 & 0.09295380660277 \\ \mathrm{C} & -14.23625397221701 & -0.45797421381730 & 0.13111939587375 \\ \mathrm{C} & -14.13482591245121 & 0.95016461978019 & 0.31274681584131 \\ \mathrm{C} & -12.88226739037940 & 1.54346798980030 & 0.48418356285828 \\ \mathrm{C} & -10.39152416790787 & 1.33260209511106 & 0.61717547435456 \\ \mathrm{C} & -9.27540065169274 & 0.51947977366222 & 0.57369987552591 \\ \mathrm{C} & -9.41164377765927 & -0.85670277564119 & 0.37761228976196 \\ \mathrm{C} & -10.65098953822003 & -1.43546234984335 & 0.21794072708181 \\ \mathrm{C} & -15.62230160129236 & -1.03501251974324 & 0.05396806807260 \\ \mathrm{C} & -16.59082166084035 & -0.04283128877416 & -0.56766764067399 \\ \mathrm{O} & -16.51866510759997 & 1.24500924257967 & 0.10055969331722 \\ \mathrm{C} & -15.32230466796599 & 1.79075508581556 & 0.36602882979822 \\ \mathrm{O} & -12.78063640447147 & 2.86744775290244 & 0.69289482084836 \\ \mathrm{O} & -10.19306087175647 & 2.64871988828369 & 0.82181602074326 \\ \mathrm{O} & -15.29403971122785 & 2.98420817914017 & 0.65998810231222 \\ \mathrm{C} & -18.05362603583495 & -0.43887024876225 & -0.45787013646610 \\ \mathrm{C} & -18.46535702268164 & -1.53528001034748 & -1.40368843102152 \\ \mathrm{O} & -19.70118920096277 & -1.99313296130243 & -1.10378226116094 \\ \mathrm{O} & -17.82202851065966 & -1.95286556262032 & -2.33126322534395 \\ \mathrm{H} & -13.17726276430009 & -2.29016643399344 & -0.05022820501076 \\ \mathrm{H} & -8.30354953491013 & 0.97638717867203 & 0.69995095801388 \\ \mathrm{H} & -8.52195922826786 & -1.47319299312004 & 0.35134239485267 \\ \mathrm{H} & -10.74437205015585 & -2.50273642777314 & 0.06555672316088 \\ \mathrm{H} & -15.62903444889205 & -1.95392711294706 & -0.53207700470506 \\ \mathrm{H} & -15.96927131151539 & -1.28343799238095 & 1.06354823680255 \\ \mathrm{H} & -16.32883031262025 & 0.11894325584501 & -1.61623989301897 \\ \mathrm{H} & -13.71849867324404 & 3.22608302352236 & 0.74227965878118 \\ \mathrm{H} & -11.05191809079193 & 3.10575579012331 & 0.83322609359210 \\ \mathrm{H} & -18.30479286077483 & -0.73019934968322 & 0.56416539218170 \\ \mathrm{H} & -18.67223046309672 & 0.43240485034344 & -0.69074206449158 \\ \mathrm{H} & -19.92691943478221 & -2.66570719557357 & -1.76616213512977\end{array}$


Heat of Formation: -1030.156778912124 Eh

Gibbs Free Enthalpy: -1029.94815384 Eh

No imaginary frequencies

$\begin{array}{clcc}\mathrm{C} & -11.35166996645877 & 0.84554248268484 & 0.52304935484320 \\ \mathrm{C} & -11.49660644988310 & -0.54552475358073 & 0.22156561170467 \\ \mathrm{C} & -12.77679109837172 & -1.05631601113911 & -0.13160541000942 \\ \mathrm{C} & -13.87110923178822 & -0.25055929998513 & -0.19545711464368 \\ \mathrm{C} & -13.75365331684890 & 1.13288637197815 & 0.12206175012811 \\ \mathrm{C} & -12.51034505508576 & 1.66778105109200 & 0.45993016242887 \\ \mathrm{C} & -10.05792433065013 & 1.34604606985485 & 0.86006054676783 \\ \mathrm{C} & -8.97083955254676 & 0.49272658453832 & 0.87672416565795 \\ \mathrm{C} & -9.13110163384813 & -0.86253810459097 & 0.58048461454712 \\ \mathrm{C} & -10.36687685304766 & -1.38157912199162 & 0.26528713388047 \\ \mathrm{C} & -15.23027843103165 & -0.72207094303192 & -0.61978569334214 \\ \mathrm{C} & -16.30677872731975 & 0.03805580708484 & 0.13572643822397 \\ \mathrm{O} & -16.13860085281633 & 1.46831196025139 & -0.05927990987623 \\ \mathrm{C} & -14.91950076539385 & 2.00874559850244 & 0.10188128872055 \\ \mathrm{O} & -12.38802151780709 & 2.97728026240635 & 0.73986573496899 \\ \mathrm{O} & -9.83772191732707 & 2.63832265229450 & 1.17173119489709 \\ \mathrm{O} & -14.84738508938222 & 3.22922964177535 & 0.22560071358145 \\ \mathrm{C} & -16.33772990672268 & -0.22197139733647 & 1.63839809445338 \\ \mathrm{C} & -16.77671500633294 & -1.61782283760325 & 1.99284242113543 \\ \mathrm{O} & -16.68882507677949 & -1.83344299955823 & 3.32180167814751 \\ \mathrm{O} & -17.16583651807675 & -2.45579283023429 & 1.21956043567568 \\ \mathrm{H} & -12.86069935832380 & -2.10833509173444 & -0.37539255951630 \\ \mathrm{H} & -8.00201189291869 & 0.90203622575714 & 1.12697400490381 \\ \mathrm{H} & -8.26413696599720 & -1.51089767143074 & 0.60124516380301 \\ \mathrm{H} & -10.48104726511470 & -2.43205784436686 & 0.03219321256041 \\ \mathrm{H} & -15.36912851866659 & -0.53034099679699 & -1.68898855806997 \\ \mathrm{H} & -15.35575614553362 & -1.79230882447232 & -0.46162833026572 \\ \mathrm{H} & -17.28419719244209 & -0.17556780273223 & -0.29058846099130 \\ \mathrm{H} & -13.28867696194289 & 3.39205388628916 & 0.58000802440056 \\ \mathrm{H} & -10.67181740410713 & 3.13314293439646 & 1.09670652202896 \\ \mathrm{H} & -15.36138400698725 & -0.04123285344894 & 2.09266356948091 \\ \mathrm{H} & -17.02839193136990 & 0.47999940491129 & 2.11142778814153 \\ \mathrm{H} & -17.00048105907717 & -2.73695154978283 & 3.48983641163328\end{array}$




\section{References}

1. Bierman, M.; Logan, R.; Obrien, K.; Seno, E. T.; Rao, R. N.; Schoner, B. E., Plasmid Cloning Vectors for the Conjugal Transfer of DNA from Escherichia-Coli to Streptomyces Spp. Gene 1992, 116 (1), 43-49.

2. Fu, J.; Bian, X.; Hu, S.; Wang, H.; Huang, F.; Seibert, P. M.; Plaza, A.; Xia, L.; Muller, R.; Stewart, A. F.; Zhang, Y., Full-length RecE enhances linear-linear homologous recombination and facilitates direct cloning for bioprospecting. Nat. Biotechnol. 2012, 30, 440-6.

3. Paget, M. S.; Chamberlin, L.; Atrih, A.; Foster, S. J.; Buttner, M. J., Evidence that the extracytoplasmic function sigma factor $\varsigma \mathrm{E}$ is required for normal cell wall structure in Streptomyces coelicolor A3 (2). J. Bacteriol. 1999, 181, 204-211.

4. Gomez-Escribano, J. P.; Bibb, M. J., Engineering Streptomyces coelicolor for heterologous expression of secondary metabolite gene clusters. Microb. Biotechnol. 2011, 4, 207-15.

5. Epstein, S. C.; Charkoudian, L. K.; Medema, M. H., A standardized workflow for submitting data to the Minimum Information about a Biosynthetic Gene cluster (MIBiG) repository: prospects for research-based educational experiences. Stand Genomic Sci 2018, 13.

6. Lomovskaya, M.; Doi-Katayama, Y.; Filippini, S.; Nastro, C.; Fonstein, L.; Gallo, M.; Colombo, A. L.; Hutchinson, C. R., The Streptomyces peucetius dpsY and dnrX Genes Govern Early and Late Steps of Daunorubicin and Doxorubicin Biosynthesis. J. Bacteriol. 1998, 180, 2379-86.

7. Krohn, K.; Vukics, K., First Chemical Synthesis of the Antiviral Agents S2502 and S2507. Synthesis 2007, 2894-900.

8. Kunnari, T.; Kantola, J.; Ylihonko, K.; Klika, K. D.; Mäntsälä, P.; Hakala, J., Hybrid compounds derived from the combination of anthracycline and actinorhodin biosynthetic pathways. J. Chem. Soc., Perkin Trans 2, 1999, 1649-52. 